\title{
Franciscanos en la Castilla Bajomedieval: El monasterio de San Francisco el Viejo de Talavera de la Reina (Toledo)
}

\author{
CÉSAR PACHECO JIMÉNEZ
}

RESUMEN

En este estudio hacemos una aproximación a la primera implantación de franciscanos en Talavera de la Reina, a través del monasterio de San Francisco el Viejo, uno de los muchos centros de la orden de menores en la Castilla bajomedieval. El convento se mantiene desde mediados del siglo XIII hasta 1494, fecha en la que se funda una nueva casa franciscana bajo la

Observancia. Analizamos el marco espacial en donde se asientan los frailes y su incidencia en el panorama religioso y civil, asi como las implicaciones que el monasterio debió de tener en la vida política del concejo.

En definitiva, un primer acercamiento al problema del franciscanismo local en una etapa de expansión y consolidación de la villa.

\section{ABSTRACT}

This study is an approach to the first settlement of franciscans in Talavera de la Reina, in the monastery of San Francisco el Viejo, one among many others centres of the order of minors, during the castilian low middleages. This convent is open from the middle of the xIII century to the year 1494, when a new franciscan house is open, according to the "Observancia" (rules). We analyze the space framework where the friars live and their influence in the religious, political and civil life of the city. In short, it is a preliminary approach to the phenomenon of local franciscanism during a period of growth and development of the city.

\section{LA PRESENCIA FRANCISCANA EN LA ZONA DE TOLEDO EN EL SIGLO XIII}

Subyace una cierta imprecisión en los datos disponibles acerca de las fundaciones pioneras de las órdenes mendicantes instaladas en la geo- 
grafía hispánica en el siglo XIII ${ }^{1}$. Con respecto a la zona de Toledo, también observamos este fenómeno, no exento de una ambigüedad producida, como dice Graña Cid, por las tradiciones legendarias y cronísticas en su deseo de ensalzar el pasado de las órdenes o de las poblaciones que historian ${ }^{2}$. Las primeras noticias que tenemos acerca de la presencia franciscana en Toledo nos sitúan en las primeras décadas del siglo XIII. Algunos autores han pretendido fijar el año 1219 para la llegada de los frailes menores a la ciudad, cuando todavía vivía San Francisco y quizá fruto de alguna misión de hermanos de la orden en tierras hispánicas. Para otros será más bien en torno a 1229-1230 cuando un grupo de franciscanos ocupa una ermita a las afueras de la urbe, en el lugar llamado La Bastida. Allí, según refiere Abad Pérez ${ }^{3}$, el primer guardián que figura es el Padre Alfonso Martín, sucedido en el cargo por fray Pedro Gallego, que en 1236 llega a ser Ministro Provincial de Castilla ${ }^{4}$.

En los años treinta se experimenta una especie de toma de conciencia del papel que juega la orden en el territorio ibérico, que se traduce pronto en la organización de las distintas provincias ${ }^{5}$. En ese proceso, las demarcaciones territoriales que se fijan a partir de 1239 son Aragón, Santiago y la provincia de Castilla, a la que pertenece la zona de Toledo, y por supuesto, Talavera de la Reina.

La política de Fernando III sin duda influyó en el establecimiento de estos colectivos mendicantes, que por otra parte, entraban en franca competencia religioso-devocional con la iglesia secular. El especial talante de predicación de estos frailes menores llega a calar profundamente en el pueblo, sobre todo en los sectores burgueses, y en los niveles oligárquicos de las sociedades locales. Los primeros ven en los mendicantes unos alia-

GrAÑA CID, Mª del Mar, «Frailes, predicación y caminos en Madrid. Un modelo para estudiar la itinerancia mendicante en la Edad Media" en Caminos y caminantes por las tierras del Madrid medieval. Madrid, 1993, págs. 281-319.

2 No es este el único aspecto que las crónicas locales de los siglos Xvl-xvill intentan ensalzar. En éstas se encuentran numerosos ejemplos de argumentos falsificadores que, maquillados con tintes de verosimilitud, intentan explicar, justificar y a la vez enorgullecer el origen remoto, o la calidad y nobleza de sus gentes, sus fundaciones religiosas, edificios, instituciones, etc. Sobre este particular puede consultarse la obra de don Julio CARO BAROJA, Las falsificaciones de la Historia (en relación con la de España). Barcelona, 1991. También la obra de Santiago QuESADA, La jdea de ciudad en la cultura hispana de la Edad Moderna. Barcelona, 1992.

3 ABAd Pérez, Antolín, O.F.M., "La biblioteca franciscana de Toledo (1284-1808)" en Anales Toledanos, vol. XX (Toledo, 1984), págs. 11-36.

4 López, Atanasio, O.F.M., La Provincia de España de los Frailes Menores, Santiago de Compostela, 1915, págs. 171-172.

5 García Oro, José, Francisco de Asís en la España Medieval. Santiago de Compostela, 1988, pág. 59. 
dos frente al descontento que esta clase tiene con el clero parroquial y que les permitía obtener un cierto prestigio social como benefactores de la comunidad religiosa, amen de costear, al igual que la nobleza, las capillas funerarias y enterramientos suntuosos ${ }^{6}$.

Está de sobra demostrado cómo el surgimiento de estos conventos, al principio, es de carácter periférico, precisamente para evitar un choque frontal con los intereses de las parroquias; mas tarde ya en los años cuarenta son asentamientos intraurbanos, dejando los primitivos recintos que solían ser ermitas o santuarios en medio del campo ${ }^{7}$. Esa vocación urbana, tan patente en el desarrollo de las fundaciones franciscanas medievales, es parte inherente de su idiosincrasia.

En el caso de la ciudad de Toledo, una vez abandonada la ermita de La Bastida se trasladan al interior del recinto urbano, donde fundan el antiguo convento de San Francisco en el último tercio del siglo XIII ${ }^{8}$. Sin embargo, nos interesa fijar bien las fechas de 1219, de la primera fundación toledana de la orden, así como la del primer convento conocido en Madrid, que debió de iniciarse en la década de los años 20, como señala Carrasco Lazareno ${ }^{9}$ y no en 12.14 como asegura la tradición ${ }^{10}$. A su vez parece que surgen centros franciscanos en otras poblaciones en franco desarrollo como Atienza, Guadalajara o Molina de Aragón. Este período cronológico es importante por su relación con las primeras apariciones de conventos franciscanos y dominicos en nuestro ámbito, por lo que hay que tenerlo en cuenta a la hora de situar el monasterio talaverano.

Si entendemos que el programa fundacional de los frailes menores está muy relacionado con el proceso de reconquista y repoblación de las tierras

\footnotetext{
6 Cuadrado Sánchez, Marta, «Un nuevo marco socioespacial: emplazamiento de los conventos mendicantes en el plano urbano" en VI Semana de Estudios Medievales (Nájera, 31 julio-4 agosto 1995). Logroño, 1996, pág. 108. Y Adeline RucQuol, "Los franciscanos en el Reino de Castilla» en Idem, pág. 68.

7 Cuadrado, Marta, op. cit.

8 Acerca de la fundación de este convento y demás pormenores de la presencia franciscana en la ciudad imperial ver el artículo de Julio PORRES MARTíN-CLETO, "LOs franciscanos en Toledo" en Anales Toledanos, vol. XVII (Toledo, 1983), págs. 17-28.

a Carrasco Lazareno, $M^{a}$ Teresa, «Los conventos de San Francisco y de Santo Domingo de la villa de Madrid (siglos XIII-XV). Breves consideraciones históricas, jurídicas y diplomáticas» en en VI Semana de Estudios Medievales (Nájera, 31 julio-4 agosto 1995). Logroño, 1996, págs. 239 y ss.

- Graña Cid, op. cit., pág. 285 y de la misma "Religiosos in via. Franciscanos y caminos en Castilla la Nueva (1215-1550)" en Actas del I Congreso de Caminería Hispánica. Guadalajara, 1993, págs. 117-148. Por su parte, Cristina Segura fija en 1217 la fundación de San Francisco en Madrid ( Julí́, S., Ringrose, D. y Segura, C., Madrid. Historia de una capital. Madrid, 1994, pág. 105).
} 
situadas al sur del Sistema Central, como apunta Graña Cid, la dispersión de estos conventos por diferentes puntos del territorio castellano meridional, parece vertebrarse en una especie de avance caminero que aprovecha la ruta hacia el sur y sudoeste, estableciendo casas en aquellas poblaciones de cierto relieve, por una parte, como Toledo, o en núcleos de población media pero con una situación expansiva de los concejos, caso de Talavera.

Además, esta vinculación caminera de las fundaciones mendicantes nace de la esencia misma de la orden, considerada más itinerante que sedentaria ${ }^{11}$, aspecto éste que sin duda influyó en la provisionalidad de sus primeros establecimientos.

\section{EL MARCO URBANO DE LA FUNDACIÓN: LA TALAVERA DEL SIGLO XIII}

La villa de Talavera en el siglo XIII era una población en proceso de consolidación como concejo. Su carácter de realengo le ofrecía un estatuto especial de privilegios pero también de indudables esfuerzos por mantener su autonomía concejil frente a las posibles ofensas contra su alfoz, en una enconada competencia con la ciudad de Ávila. Esta situación le lleva a firmar un pacto de Hermandad con el naciente concejo de Plasencia, con el que los abulenses también habían tenido conflictos jurisdiccionales, en sendas cartas de $1248{ }^{12}$ y $1274{ }^{13}$. Esta actitud es sólo el fiel reflejo de los momentos cruciales que vive la villa tras unas décadas de inquietantes altibajos en su desarrollo.

Tras la toma de Talavera por el rey Alfonso VI, que tuvo lugar entre 1083 y 1086, bien como fruto de conquista o como parte del pacto con alQadir para la entrega de Toledo y de otros núcleos circundantes de la taifa toledana ${ }^{14}$, el área, y antiguo distrito, de Medina Talabira formaba un

1 Graña Cid, «Religiosos in via...", pág. 128.

12 GómEz MENOR, José, La antigua Tierra de Talavera: Bosquejo histórico y aportación documental. Toledo, 1965, págs. 57-58. PACHECO JIMÉNEZ, C., «Carta de Hermandad entre los concejos de Plasencia y Talavera para la defensa mutua frente al concejo de Ávila (1248)" en Cuaderna (Revista de estudios humanísticos de Talavera y su antigua tierra), no 4 (septiembre, 1996), págs. 115-117.

13 Berjano, Daniel, «Antigua carta de hermandad entre Plasencia y Talavera (1274)" en Boletín de la Real Academia de la Historia, t. XXXV (1899), págs. 317-318.

14 Sobre la fecha exacta de la toma de Talavera no hay unanimidad. Algunos autores (JIMENEZ DE Gregorio, Gómez MENOR) basándose en la Crónica del obispo Pelayo (edición de B. SÁnchez Alonso, Madrid, 1924) la fijan en el 1083, antes pues de la de Toledo (1085). Otros como Julio González (Repoblación de Castilla la Nueva, Madrid, 1975-1976) lo consideran más bien como un 
extenso territorio por repoblar y reaprovechar. Los planes de colonización en este área vendrán determinados por los posteriores ataques y saqueos almorávides, especialmente el de 1109 y 1110, que llegan a tomar la villa ${ }^{15}$. Estas ofensivas retrasaron los planes de repoblación, dificultad que parece manifestarse todavía en el reinado de Alfonso VII, en el que este territorio se caracteriza por una debilidad demográfica y militar ${ }^{16}$. La llegada de mozárabes de Al-Andalus y el progresivo cese de los ataques norteafricanos influyeron en una lenta recuperación y paulatina consolidación del concejo y su tierra. Talavera vive entonces un período de cierta inseguridad, donde el factor militar tiene más peso que el civil, que se manifiesta en la mejora de sus defensas fortificadas y en la implantación de un sistema de milicia concejil. Esta protagonizará uno de los ataques desafortunados contra la Sevilla almohade en 1213 según nos refieren los Anales Toledanos ${ }^{17}$. La expedición de ese ejército denota ya una cierta consolidación del concejo y la articulación de una estructura social militarizada.

En 1152 Alfonso VII delimita los concejos de Ávila y Talavera ${ }^{18}$, por el sector norte y oeste de la tierra talaverana, frontera que no estuvo exenta de conflictos tanto por las incursiones de los talaveranos en el alfoz abulense como por las ofensivas de los caballeros de Ávila contra el territorio del valle del Tajo ${ }^{19}$. No será hasta 1232, una vez que Trujillo es capturada por tropas cristianas, cuando la ocupación y organización de la tierra de Talavera se hace más patente ${ }^{20}$. La seguridad militar y el asentamiento de

resultado del acuerdo global del pacto de entrega de Toledo. Por su parte, el cronista musulmán Ibn al-Kabaroús (Historia de al-Andalus, edición de Felipe Maílio Salgado, Madrid, 1993, pág. 108), relata que la posesión de Talavera por el rey Alfonso se produce por campaña militar con posterioridad a la toma de Toledo.

15 Martínez Lillo, S., «Talavera de la Reina en las fuentes medievales» en Cuaderna (Revista de estudios humanísticos de Talavera y su antigua tierra), $\mathrm{n}$ - 4 (septiembre, 1996), págs. 78-80.

16 IZQUIERDO BENITO, Ricardo, Reconquista y repoblación de la tierra toledana. Temas toledanos, $n^{\circ} 29$. Toledo, 1983, pág. 30. Sobre el alfoz medieval de Talavera puede consultarse, entre otras, las siguentes obras: JIMÉNEZ DE GREGORIO, F., El alfoz de Talavera y sus montes. Talavera, 1981. SuÁREZ ÁlvAREZ, Ma Jesús, La Villa de Talavera y su Tierra en al Edad Media (1369-1504). Oviedo, 1982. Gómez MenOR, op. cit.

17 Anales Toledanos I, pág. 354: «Arrancada sobre CCCC peones e LX caballeros de Talavera, alende Guadalquivir cerca de Sevilla, que non escaparon ende sin no muy pocos, primer dia de julio. Era MCCL/» en Julio Porres MARTín-Cleto, Los Anales Toledanos I y II. Toledo, 1993, pág. 177.

${ }_{18}$ Archivo Municipal de Talavera, Privilegios, leg. 1, no 13 . Traslado del siglo XV. Transcrito por GÓMEZ MENOR, op. cit., pág. 53.

19 Moreno Núñez, J. Ignacio, Ávila y su Tierra en la Baja Edad Media (siglos xill-XV). Valladolid, Junta de Castilla y León, 1992, págs. 35-36.

20. Rodriguez-Picavea Matilla, Enrique, La Villa y la Tierra de Talavera en la Plena Edad Media: Orígenes, consolidación y crecimiento de un concejo de realengo (siglos XIII-XV). Talavera de la Reina, Excmo. Ayuntamiento, 1996, pág. 29. 
repobladores, así como la reactivación de la economía agropecuaria ${ }^{21}$ son factores que sin duda influyeron en el crecimiento socioeconómico del concejo. En este siglo XIII, en otras zonas del alfoz de Talavera van surgiendo nuevo señoríos, fruto de concesiones reales a determinados miembros de la nobleza o a comunidades religiosas de gran peso ${ }^{22}$.

Desde el período de la repoblación y ocupación del área geográfica rural y urbana, así como durante el siglo XII y XIII, diferentes instituciones se harán con propiedades en la villa. Es el caso de las Ordenes Militares de Calatrava ${ }^{23}$, de Santiago ${ }^{24}$, Hospital de San Juan de Jerusalén y la de Monfragüe ${ }^{25}$, o los poderosos monasterios de San Clemente de Toledo y las Huelgas de Burgos, que adquieren numerosas propiedades de mozárabes ${ }^{26}$. Por su parte, los arzobispados de Santiago de Compostela y Toledo también contaban con importantes propiedades en el término de Talavera. Esta incursión de señoríos representaba un factor determinante en la estructura de la propiedad de la tierra e influía en el marco social de la villa y su alfoz. Una sociedad local esencialmente plural, donde grupos étnico-religioso-culturales conviven en un mismo núcleo: mozárabes, cris-

21 Un buen ejemplo del despegue económico del concejo es la celebración anual de una feria de ganados, que Sancho IV concede a Talavera en 1294, en torno al día de San Andrés (A.M.T , Privilegios, leg. 1, s/n,: publicado por Mercedes GalBrols, Historia del reinado de Sancho IV. Madrid, 1922-28, vol. III, doc. $n^{\circ} 584$.) Esta feria suponía un foro mercantil y de intercambio de gran magnitud para la villa y su zona de influencia. LADERO QUESADA, M.A., Las ferias de Castilla. Siglos XII al XV. Madrid, 1994.

22 El fenómeno de la disgregación del primitivo territorio viene dado por la aparición de diferentes estados señoriales como el de Velada, Navamorcuende-Cardiel, antiguamente adscritos al concejo de Ávila (vid. MORENo NúÑEZ, op. cit.); después la creación, a finales del siglo XIII, del señorio de Cervera y el de Mejorada y Segurilla por privilegios de Sancho IV y sus cartas pueblas: Alfonso FRANCo SILVA, «La fundación de pueblas en tierras situadas al noroeste del reino de Toledo a fines del siglo XIII" en Historia, Instituciones, Documentos (Sevilla, 1990), págs. 31-53. En el caso de la creación de la villa de Azután por el Monasterio de San Clemente de Toledo, en la zona suroccidental del alfoz de Talavera se pueden consultar los trabajos de J. Carlos VIZUETE MENDOZA, “El Monasterio de San Clemente en la Edad Media» en Anales Toledanos, vol. XXX (Toledo, 1993), págs. 7-57 y Azután en el Antiguo Régimen, Cuenca, 1993. Del mismo autor es la obra La formación de un gran dominio en la Tierra de Talavera: Santa María de Guadalupe (Estudio y Regesta, 1340-1389). Talavera de la Reina, Excmo. Ayuntamiento, 1993, en el que se ocupa del famoso monasterio y su incidencia en la tierra talaverana. Por último, sobre los señoríos toledanos de esta zona puede consultarse la obra genérica de Salvador de Moxó, Los antiguos señorios de Toledo, Toledo, 1973.

23 Rodriguez-Picavea Matilla, Enrique, La formación del feudalismo en la meseta meridional castellana: Los señoríos de la Orden de Calatrava en los siglos XII-XIII. Madrid, 1994, págs. 129130.

24 Del Cerro del Valle, Ángel, La Encomienda Santiaguista del hospital de Talavera (14941537). Toledo, 1984.

25 Rodríguez-Picavea, La Villa y la Tierra de Talavera..., op. cit., págs. 36 y 40.

26 Ibídem, págs.41-46. Sobre la documentación de propiedades mozárabes vid. GoNZÁLEZ Palencia, Ángel, Los mozárabes de Toledo en los siglos XII y XIII, 4 vols. Madrid, 1926-1930. 
tianos no arabizados (castellanos, francos, gallegos, etc. que se asientan con la repoblación), judíos y mudéjares; un mosaico social común a otras poblaciones del reino de Toledo.

Mientras que el papel de los vecinos mozárabes y castellanos va a determinar el devenir político de la villa durante el siglo XIII, las minorías judía y mudéjar quedan relegadas a un segundo plano como agentes pasivos de las decisiones concejiles. La dualidad en la administración de justicia con dos alcaldes diferentes, uno para la comunidad mozárabe y otro para el vecindario de castellanos, se enmarca en un proceso de diferencias entre ambos colectivos que además ocupan espacios representativos diferentes: los mozárabes en la "Villa» o núcleo urbano más antiguo, y los castellanos en los arrabales. Antes este desencuentro, que produjo la formación de bandos en favor de causas reales distintas en el conflicto bélico entre Alfonso $X$ y Sancho IV, el rey sabio intentó solucionarlo mediante la designación de un sólo alcalde que juzgara a ambos grupos, si bien los mozárabes se regirían por el Fuero Juzgo y los castellanos por la Ley de las Partidas; después con el ánimo de establecer un equilibrio entre ambas partes el mismo rey dispone la vigencia unitaria del Fuero Real en 1257, quedando invalidado el resto de fueros vigentes hasta $1254{ }^{27}$.

En Talavera, la existencia y surgimiento de parroquias se da con cierta rapidez, a medida que la repoblación de la villa se articula en función del espacio urbano que se desarrolla a partir del primer núcleo romano y musulmán, que se corresponde con el llamado en las fuentes tardías "cuerpo de la villa», o sea, el primer recinto amurallado. En éste se registra el asiento de parte de la población mozárabe, que bajo la dominación musulmana debió de vivir en zonas de extramuros, y un nutrido colectivo mudéjar al que tras la conquista se le permitió seguir disfrutando de sus viviendas y propiedades ${ }^{28}$; además algunos vecinos de la comunidad judía también ocupan casas en el seno del primer recinto ${ }^{29}$, llegando a conformar en el siglo XV su judería a espaldas de la iglesia mayor de Santa María y del monasterio de Santa Catalina de los padres jerónimos ${ }^{30}$.

\footnotetext{
27 JimÉnEz de Gregorio, Fernando, Los pueblos de la provincia de Toledo hasta finalizar el siglo XVIII. Talavera de la Reina. Toledo, 1983, pág. 115. Sobre los fueros de Toledo vid. Crisanto Rodríguez-Arango, El derecho en Toledo, Temas Toledanos n²39. Toledo, 1984; A. García Gallo, «Los fueros de Toledo» en $A H D E, 45$ (1975) y José ALVARADO PLANAS, «Los fueros de concesión real en el espacio castellano-manchego (1065-1214). El Fuero de Toledo» en Espacios y fueros en Castilla-La Mancha (siglos XI-XV): Una perspectiva metodológica. Madrid, 1995, págs. 91-139.

28 SuÁrEZ ÁlvaREZ, op. cit., pág. 135.

29 LEÓN TELLO, Pilar, Judíos de Toledo. Madrid, 1979.

30 PACHECo JimÉnez, César, La comunidad judía de Talavera de la Reina en el siglo XV, en prensa.
} 
Fuera de este núcleo, la villa crece por el norte y este, área suburbana denominada Arrabal Mayor, donde se asientan preferentemente los nuevos repobladores castellanos, gallegos, francos y parte de la comunidad judía; la actividad predominante será la mercantil y artesanal unida a su idiosincrasia agropecuaria.

Los Arrabales Viejos, situados en el oeste de la Villa, y antiguamente ocupados por los mozárabes, estaban dedicados a huertos o "cortes", constituyendo una especie de transición entre lo urbano y lo rural ${ }^{31}$. Además algunos autores, como Julio González o José Gómez Menor han situado en este área la zona de mercados y tiendas que menciona la documentación mozárabe de los siglos XII y XIII. Todo este arrabal estaba cercado con una muralla que debió de construirse en los primeros años del siglo XII, y en la cual se abría una puerta importante, la de Cortes o Cuartos, y también un postigo conocido en el siglo xIII por postigo de San Antolín ${ }^{32}$. Extramuros de esta cerca un territorio de huertas, olivares y algunas zonas boscosas en torno al río. El arrabal cobra sin embargo, especial interés para ciertas instituciones religiosas que se establecen en él al amparo de una dinámica actividad demográfica y económica, de tal manera que en el siglo XIII esta parte era una de las más pobladas de la villa, y sin duda, acogía a una población muy diversa de distinto origen social ${ }^{33}$.

\subsection{La organización eclesiástica en la villa en el siglo xIII: parroquias y otros centros religiosos}

El panorama que ofrece la organización eclesiástica en Talavera es decididamente ilustrador del esfuerzo que el concejo realiza para la asignación de espacios religiosos en el entramado urbano. Una dispersión de templos e iglesias que responde a la progresiva implantación de colectivos vecinales que asumen la identificación de la parroquia como lugar de referencia en el organigrama sociourbano de la villa.

31 Es indicativo el nombre de uno de los accesos a este tercer recinto o Arrabal Viejo, cuya referencia más antigua es de un documento de 1142 (Carmen ToRrojA, Catálago del Archivo del Monasterio de San Clemente. Toledo, 1973, doc. $n^{\circ} 3$ ). Nos referimos a la Puerta de Cortes, posteriormente conocida como Puerta de Cuartos. Sobre la evolución histórica de esta zona de la ciudad vid. César PACHECO, El barrio de la Puerta de Cuartos: Historia social y cultural. Talavera, 1993.

32 Pacheco Jiménez, C., Las antiguas puertas de Talavera de la Reina, inédito.

33 En palabras del licenciado Sigüenza, refiriéndose al barrio en tiempos de Sancho IV: «...se dice que en aquel tiempo, lo más poblado era lo que ahora se llama barrio de San Estevan, San Andrés y la Puerta de Cuartos, que todo ello esta cercado de muralla». PACHECO JiMÉnEZ, El Barrio..., pág. 25. 
La primera medida de tipo eclesiástico que se tomó en la Talavera cristiana fue la creación de un arciprestazgo cuya jurisdicción venía a coincidir con los límites del alfoz, y que a su vez estaba incluido en el arcedianato de Talavera, junto a Maqueda, Santa Olalla y Escalona ${ }^{34}$. Se fecha en torno a mediados del siglo xII la constitución del arciprestazgo de la urbe, si bien la primera referencia nominal de un arcipreste talaverano es de un documento de $1178{ }^{35}$; pero el mismo planteamiento de este organigrama nos revela que la constitución de una red parroquial básica está fraguada mucho antes de regularizarla con la fórmula del arciprestazgo.

La parroquia es un elemento esencial para comprender la organización social y espacial de la población. Reúne diversas competencias: edificio de culto, comunidad de receptores de sacramentos y de futuros enterrados en un mismo templo y circunscripción territorial de administración eclesiástica ${ }^{36}$.

La instrumentalización del espacio urbano por diferentes grupos sociales es una constante en la historia de la ciudad e impone una determinada concepción del sistema organizativo de las colaciones. Nos referimos fundamentalmente a la aparición de las iglesias parroquiales de acuerdo con las exigencias de un vecindario en fase de crecimiento. Por un documento de $1154{ }^{37}$ conocemos la relación de las primitivas parroquias existentes en Talavera: Santa María, San Pedro, Santiago, San Clemente, Santo Domingo ${ }^{38}$, Santa Eugenia, Santa Leocadia, San Miguel, San Salvador y San Martín. De esta lista, las más antiguas, creadas a finales del siglo XI, fueron Santiago ${ }^{39}$ y Santa María. Esta última obtiene el título de Colegiata en 1211, sin duda, por ser la más importante y la de mayor ascendencia y antigüedad ${ }^{40}$. Se convierte así en la institución religiosa local más impor-

34 Rodríguez-Picavea, La Villa y la Tierra..., cit., págs. 73-74.

35 González Palencia, op. cit., l, doc. n² 141.

36 García de Cortázar, J. Ángel, La sociedad rural en la España Medieval. Madrid, 1988, pág. 90 .

37 Archivo Histórico Nacional, Códices 996B, fol. 100. Transcrito en Francisco J. HERNÁNDEZ, Los cartularios de Toledo. Catálogo documental. Madrid, 1985, págs. 95-97.

38 Esta iglesia de Santo Domingo estaba vinculada al Monasterio de San Clemente de Toledo, y se encontraba en el interior del primer recinto amurallado; no hay que confundir con la otra iglesia de Santo Domingo y San Ginés, fundada por los dominicos en el siglo XVI y ubicada en la calle del mismo nombre, en el barrio de la Puerta de Cuartos.

39 La iglesia de Santiago, situada en el arrabal Mayor, cerca de la Puerta de Zamora, aparece en un documento fechado en 1099 , en el que Alfonso VI da al monasterio toledano de San Servando y San Germán varias propiedades, entre las que se cuenta la iglesia de Santiago de Talavera (Archivo Catedral de Toledo, sign. V.11.B.1.4.)

40 Archivo de la Colegiata de Talavera, carp. 561, $n^{\circ} 2$. Mediante este documento, fechado en Toledo en julio 1211, Don Rodrigo, arzobispo de Toledo, con la aprobación de su cabildo erige en colegial la parroquia de Santa María de Talavera, instituyendo en ella las dignidades de deán, 
tante con una supremacía sobre el resto de las parroquias, hecho éste que acarreará no pocos conflictos de competencia.

La de San Pedro, San Clemente y las demás surgieron en las primeras décadas del siglo XII, mientras que, ya en el siglo XIII, se documenta otra nueva parroquia, la de Santa Justa ${ }^{41}$. Once parroquias que se diseminaban por el entramado urbano formando colaciones tanto civiles como eclesiásticas. La distribución con respecto a las tres grandes áreas de la villa era la siguiente en el siglo XIII:

\section{Cuerpo de la Villa}

Arrabal Mayor
Santa María, San Pedro, San Clemente

Santo Domingo y Santa Justa

Santa Leocadia, Santa Eugenia, Santiago

San Miguel, El Salvador, San Martín.

Arrabal Viejo

San Esteban? ${ }^{42}$

Interesa conocer esta red parroquial y su asentamiento espacial porque, en la medida en que estos centros religioso-administrativos van marcando su territorio, no quedaría zona urbanizada u ocupada por la vecindad no sujeta al control de la colación. El resto del espacio suburbano tiene un carácter residual y marginal y viene a corresponder a zonas que quedan fuera de los circuitos amurallados, los llamados «extramuros» de

sodeán, capiscol y tesorero. Publicado en Francisco J. Hernández, Los Cartularios de Toledo. Catálogo documental. Madrid, $1985, \mathrm{n}^{\circ} 318$.

${ }_{41}$ Rodríguez-Picavea incluye en esta lista la iglesia de San Antolín considerándola como parroquia dentro del casco urbano. Sin embargo, se trata de la iglesia del primitivo monasterio de monjas de San Benito situado a un par de kilómetros al noroeste de Talavera, en zona de huertas de labor. En un documento de los mozárabes publicado por González Palencia, I, nº 224, fechado en marzo de 1192, se registra una huerta en el término de la iglesia de San Antolín de Talavera. Este emplazamiento debió de abandonarse ya en el siglo xIII cuando la orden benedictina pasa a fundar un nuevo monasterio junto a la iglesia de San Clemente.

42 Hay una sorprendente ausencia de noticias en las fuentes de esta época acerca de la iglesia de San Esteban, templo que según las crónicas locales fue utilizado por los mozárabes para el culto cristiano durante la ocupación musulmana de la villa. En la Historia de Talavera de García FERNÁNDEZ (1560) se recoge una mención de la iglesia en este sentido: "Hombres ançianos ay que se acuerdan de no auer en ellos (Arrabales Viejos) vezindad alguna, aunque siempre se mostravan çímientos, otras señales de que claramente se conosçía auer auido poblaçión y espeçialmente una iglesia que se llama Sancto Esteuan la qual tiene oy el mismo nombre; y está en medio de una plaça cuadrada, no ay en ella mas de alguna parte de tapiería a la qual los vezinos çercanos tienen una reverençia como a lugar sagrado». Por nuestra parte, ante la ausencia de datos fiables entendemos que este templo pudo quedar en desuso tras la ocupación cristiana de la ciudad, lo que explica su ausencia en la lista de 1154, y posteriormente en la Baja Edad Media, cuando el barrio sufre una despoblación importante. PACHECO, C. El barrio de la Puerta de Cuartos, cit., págs. 32-34, 
la villa ${ }^{43}$. Queremos resaltar este aspecto pues se relaciona en gran medida con el asentamiento de la fundación franciscana como ya veremos.

Por lo que atañe a los centros religiosos regulares asentados en la villa, en primer lugar destacaremos al Monasterio de San Benito, de monjas cistercienses que según las crónicas, estuvo primeramente asentado en un pago a las afueras de Talavera ${ }^{44}$, para pasar después a fundar una nueva casa en el sitio que hoy ocupa, cerca de la antigua Puerta de Mérida o San Clemente, sobre los restos de una primitiva iglesia de San Marcos que mencionan las fuentes cronísticas ${ }^{45}$. Estas mismas apuntan la fecha de 1126 para la nueva fundación, sin embargo tenemos reparos para aceptarla y nos inclinamos más bien por considerar el antiguo recinto monacal intraurbano obra del siglo XIII, esto sin perjuicio de que las religiosas pudieran haber habitado en el interior de la villa en ciertos períodos de más inseguridad, fruto de los ataques almorávides y almohades a la tierra de Talavera.

El convento e iglesia cisterciense de Santo Domingo, que aparece ya en documentos del siglo xIl, puede considerarse el más antiguo de los establecidos en la villa. Se trataba de un convento filial del Monasterio de San Clemente de Toledo y su fundación, en las primeras décadas del siglo, respondía a una política de la orden toledana para canalizar la adquisición de nuevas propiedades en la villa de Talavera y su alfoz ${ }^{46}$.

Si embargo, las crónicas locales se empeñan en señalar que el primero en antigüedad de los monasterios fundados fue el de San Benito, seguido del convento franciscano que nos ocupa. Al margen de esta polémi$\mathrm{ca}$, que puede resultar estéril en este marco, observamos que la presencia de órdenes religiosas en Talavera en el siglo XIII es importante. Pues apar-

43 Obviamente hay que hacer la salvedad de ciertos edificios, como la ermita de Nuestra Señora del Prado, que, aunque estaba situada en un punto alejado de la población, representa un lugar de especial relevancia de la religiosidad colectiva y por tanto centro de atención no sólo local sino comarcal.

${ }_{44}$ En el lugar denominado San Antolín, por la advocación que tenía la iglesia conventual.

45 FERnÁNDEZ y SÁNCHEZ, Ildefonso, Historia de la Muy Noble y Muy Leal Ciudad de Talavera de la Reina. Talavera, 1896, pág. 266. Acerca de esta antigua iglesia de San Marcos no se ha localizado ninguna referencia documental y las noticias que hay se basan en la tradición cronística. Esto nos hace pensar en que puede tratarse de una iglesia que desapareción al crearse la parroquia de San Clemente, que estaba próxima al monasterio de San Benito, y parte de la cual ha sido posible documentar en unas excavaciones arqueológicas en febrero de 1997. En esta intervención aparecieron restos de una necrópolis plenomedieval cristiana (siglos $X 1-X I 1)$ que, en principio, puediera adscribirse a la antigua parroquia de San Marcos (Vid. Moraleda, A. y. PACHECO, C. "Arqueología medieval en Talavera de la Reina I: La necrópolis de la calle San Clemente", en Homenaje a don Fernando Jiménez de Gregorio, Talavera, en prensa).

4ล̂ Vid. Rodriguez-Picavea, op. cit., pág. 42 
te de las mencionadas, hay que subrayar la de las órdenes militares ya aludidas, y especialmente la de Santiago que crea el Hospital de Santiago de los Caballeros ${ }^{47}$. También se especula con la posible erección de un convento de la Santísima Trinidad en este siglo sin que de momento sea posible acreditarlo documentalmente.

Con esto podemos dibujar un perfil aproximado del ambiente religioso que vive la población a la llegada de los franciscanos. Una serie de intereses de instituciones eclesiásticas de regulares que mantienen propiedades con alta rentabilidad y posibilidades de transacción mercantil, junto a la influencia de las parroquias, verdaderas células vertebradoras de la organización del diezmo y los sacramentos.

\section{LA FUNDACIÓN FRANCISCANA. EL MONASTERIO DE SAN FRANCISCO EL VIEJO O EXTRAMUROS}

Como ya dijimos, el Arrabal Viejo era una zona de transición entre lo urbano y lo rural, donde la presencia de vencindario estuvo sometida a fluctuaciones en la Baja Edad Media. Si admitimos la existencia de la parroquia de San Esteban ya en el siglo xlit, ésta será posiblemente la única iglesia en este sector de Talavera si exceptuamos el Hospital santiaguista, creado en 1226, por iniciativa de Alfonso Téllez y su mujer Teresa Sánchez, con el objetivo de la redención de cautivos ${ }^{48}$. Su recinto se situaba muy cerca de la iglesia de San Esteban ${ }^{49}$, en un lugar intramuros del arrabal viejo y teniendo en cuenta la situación de un barrio que en esta época era populoso y activo económicamente ${ }^{50}$.

El colectivo franciscano debía elegir un punto del área periférica de la ciudad en que no entrasen en abierta competencia con otras instituciones religiosas; a pesar de la proximidad del referido Hospital y la iglesia de $\mathrm{n}^{0} 7$.

47 El documento de creación está fechado en 25 de abril de 1226. A.H.N. Uclés, carpeta 323,

48 Sin duda la experiencia del fracaso de la ofensiva talaverana a Sevilia en 1213 influyó en la elección de esta villa para su instalación. Sobre este hospital vid. la obra citada de DEL CERRO DEL. VALLE.

49 Los restos del hospital se limitan al abside mudéjar y parte de los muros laterales, edificio conocido como Santiaguito, en la calle de Templarios, y rehabilitado para futuro centro cultural.

50 Por los datos arqueológicos obtenidos en una excavación junto al Hospital se deduce que el barrio no fue ocupado de una manera estable hasta el siglo XIII, siendo muy circunstancial y provisional el asentamiento en época romana y musulmana. (Vid. MoraledA, A. y PACHECO, C. Memoria de los trabajos arqueológicos realizados en el solar $n^{\circ} 43$ de la calle Templarios de Talavera de la Reina, Consejería de Educación y Cultura, Junta de Comunidades de Castilla-La Mancha, inédito. 
San Esteban, el lugar elegido se situaba fuera de la muralla del Tercer recinto que cercaba el Arrabal Viejo, próximo al río Tajo y junto a una encrucijada de caminos y una cañada que, desde el norte venía hasta la oriIla del río ${ }^{51}$; concretamente en una huerta conocida actualmente como «Huerta de Benito» en la acera derecha del Paseo Juan de Mariana, paraje que a raíz de la fundación de la Real Fábrica de Seda, Oro y Plata de Talavera en 1748 fue acondicionado para Paseo Nuevo o de la Fábrica. A la salida de la Puerta de Cuartos dos vías importantes formaban una bifurcación, una en dirección a Alcolea de Tajo ${ }^{52}$, ruta que se convertiría desde el siglo XIV en el conocido Camino Real a Guadalupe ${ }^{53}$, y un Camino Real que tomaba dirección Extremadura por Oropesa ${ }^{54}$.

El proyecto franciscano en Talavera parece responder a la tónica general seguida en otros lugares, formando, como apunta Graña Cid «una línea racional de establecimientos cuyos puntos de conexión son estas poblaciones, pero con una importancia militar y estratégica que las convierte en los epicentros organizadores del territorio tras el avance reconquistador» 55 .

La cuestión que se plantea es analizar hasta que punto centros religiosos como el convento de los frailes menores, o el Hospital de los santiaguistas pudieron servir de focos regularizadores del ascenso demográfico del arrabal viejo. Si nos atenemos a una concepción más centrada en la parroquia, como célula activa de organización socioespacial, observa-

51 El topónimo «Cañada de la Sierra» (antiguamente Cañada de la Huerta de la Sierra) que conserva una calle que discurre en sentido norte-sur por fuera de la desaparecida Puerta de Cuartos, y que viene a unirse con el Paseo de Juan de Mariana, hasta el siglo xix denominado «Cañada de la Magdalena» son pruebas evidentes de la primitiva funcionalidad de esta zona extramuros al oeste de la villa.

52 Alcolea de Tajo, a escasos kilómetros de Puente del Arzobispo, fue una antiguo enclave islámico dondado por el rey Alfonso $\mathrm{VI}$ a la catedral de Toledo en diciembre de 1086 . Archivo de la Catedral de Toledo, sig. O.2.N.1.1.

53 El Camino de Talavera a Guadalupe por Alcolea aparece ya descrito en el Libro de Montería (siglo XIV). Vid. CRIADO DE VAL, Manuel, Teoría de Castilla La Nueva: La dualidad castellana en el lengua, la literatura y la historia. Madrid, 1969, pág. 55.

54 Sobre los caminos y cañadas de la zona de Talavera en esta época, vid. SUÁREZ ÁLVAREZ, $M^{a}$.J., "Las vías de comunicación en la zona de Talavera en el período bajomedieval» en Actas de las primeras jornadas de Arqueología de Talavera de la Reina y sus Tierras. Toledo, 1992, págs. 201-214. RuIz, Samuel, «Las cañadas de Talavera y su Tierra en el siglo XV» en Cuaderna, № 1 (Talavera, 1994), págs. 18-31. Del mismo autor la tesis de licenciatura inédita de la Universidad Complutense: Vias medievales en la provincia de Toledo: Análisis arqueológico e interpretación histórica. Madrid, 1994, fols. 205-207. También PACHECO, César, «Infraestructura viaria y hospedaje en Talavera. Siglos XVl-XVI\}» en Actas del // Congreso Internacional de Caminería Hispánica. Madrid, 1996, tomo II, págs. 385-411.

55 GRAÑA CID, «Frailes, predicación...», pág. 285. 
mos que la iglesia de San Esteban asumía el papel de epicentro de la ordenación física del vecindario, aun teniendo en cuenta la realidad arquitectónica del recinto amurallado que cercaba el barrio por el borde oeste.

Si bien en otras poblaciones, caso de Madrid, las casas franciscanas influyeron en el crecimiento y aglutinación del caserío dando lugar a arrabales, en Talavera pensamos que el grueso del arrabal estaba ya en proceso de formación y consolidación cuando vienen a asentarse los franciscanos, siempre con las particularidades antes aludidas de servir de espacio de transición entre lo estrictamente urbano y lo rural. La situación que los frailes toman, extramuros, representa una característica frecuente de las fundaciones en esta época. Pensar que no pudieron encontrar un lugar apropiado dentro del recinto urbano, a pesar de que en estos momentos el arrabal viejo disponía de espacios libres de edificaciones - los referidos «cortes» o huertos entre el caserío- supone ignorar otros requisitos que los centros franciscanos tenían en sus fundaciones.

Otro aspecto no menos importante es la fecha de establecimiento de los frailes en su nuevo convento talaverano. Sobre este particular, y como sucede con otras muchos centros de frailes predicadores, se juega con noticias imprecisas. Hay una ausencia significativa de referencias documentales al respecto pero las fuentes cronísticas de la orden sostienen su franca antigüedad, La obra del Padre Pedro de Salazar, O.F.M., Crónica de la Provincia de Castilla de $1612^{56}$ nos relata lo siguiente: «Esta provincia de Castilla tuvo un convento muy antiguo, el qual han querido algunos dezir que le fundó un compañero del glorioso padre San Francisco; el qual estuvo en el sitio y contorno de la parroquia de la Madelena. Este fue un convento más antiguo que ninguno de los que ay en la villa de Talavera, porque esta provincia de Castilla fue la más antigua que huvo en España, como consta del tiempo de su fundación, y en ella se cuenta el convento de San Francisco de Talavera, poniendo sólo dos por más antiguos, que son Madrid y Toledo...y llamóse San Francisco el Viejo, a diferencia del que después se edificó...dentro de la villa ${ }^{57}$, y por eso el otro se llama estramuros en el sitio que queda dicho en la ribera del Tajo, en el camino que va de Talavera a Puente del Arçobispo» 58.

56 Crónicas Franciscanas de España. Volumen sexto: Crónica de la Provincia de Castilla por el Padre Salazar O.F.M., prólogo del Padre Antolín Abad Pérez, O.F.M. Edición facsímil de la de 1612. Madrid, Editorial Cisneros, 1977.

57 Se refiere al convento de San Francisco, fundado hacia 1494, que estaba situado en la calle del mismo nombre, y del que sólo queda la iglesia, convertida en parroquia en el siglo XIX.

58 lbídem, Libro III, capítulo $X$ «De los conventos que esta Provincia ha tenido en la villa de Talavera", pág. 254. 
Lógicamente, esta noticia no es absolutamente concluyente dado que el autor se basa más en datos un tanto vagos y fundamentados en la tradición más que en la realidad histórica. Por ello debemos considerarla en su justa medida. La primera referencia documental que hemos localizado de la presencia franciscana en Talavera data de $1296^{59}$; en una carta otorgada por doña María de Molina, regente durante la minoría de edad del futuro Fernando IV, el 22 de febrero de ese año en la que intenta establecer concordia entre los mozárabes y castellanos de la villa. Aunque la mención es significativa tan sólo supone un punto de partida para establecer el marco cronológico en donde ha de enclavarse el monasterio franciscano.

El problema surge a la hora de fijar la aparición del mismo. De momento la arqueología no puede aportar información complementaria hasta que no se efectúen excavaciones sistemáticas en el solar donde todavía quedan restos del conjunto franciscano ${ }^{60}$. Bajo la perspectiva del control del espacio urbano por parte de otras instituciones caben dos posibles hipótesis para el origen del convento:

1. Desde un primer momento, en torno a 1219-1220, los frailes procedentes de Toledo o Madrid, fundan una casa de manera intencionada en un punto periférico de la villa, por razones de la regla fundacional: en el radio urbano, extramuros de la ciudad y en zona marginal de las parroquias ${ }^{61}$. Este lugar reunía las condiciones óptimas que les permitía, como analiza Graña Cid en otras fundaciones ${ }^{62}$, mayor libertad de acción, al no tener que depender de la apertura o cierre de las puertas de la ciudad. Además ese carácter semieremítico del convento les ponía en contacto con el entorno urbano campesino de los alrededores, así como con los ciudadanos de la urbe, de acuerdo con los ideales de San Francisco. A su vez, servían de centros de acogida de más fácil acceso para los fieles ${ }^{63}$.

59 Benavides, Antonio, Las memorias del rey Fernando IV de Castilla. Madrid, 1860, vol. II, pág. 72. doc. 51. En el documento de conformación del concejo, fechado el 11 de marzo se registra el sello del convento franciscano: "E para que esto sea firme mandamos facer dos cartas partidas por $a, b, c$, firmadas de los escribanos de Talavera e selladas con el nuestro sello del concejo de Talavera, e con los sellos del convento de frailes menores, etc."

60 Los restos arquitectónicos visibles en la acera derecha del actual Paseo Juan de Mariana, frente a la calle Templarios, en principio pueden pertenecer a la ermita de la Magdalena, erigida en el siglo XVI aprovenchando la iglesia del convento franciscano.

61 Según GaRcía Oro éstas eran las características dominantes de los conventos a partir de los años 40 del siglo xill. San Francisco de Asís en la España Medieval, cit., pág. 60.

62 GRAÑA CID, «Religiosos in via...», pág. 135.

63 Merlo, Grado G., «Eremitismo nel francescanesimo medievale» en Eremitismo nel francescanesimo medievale. Atti del XVII Convegno Internazionale. Assisi, 1991, pág. 37. 
2. Una segunda posibilidad es que la fundación franciscana se hiciera realidad con posterioridad a la constitución del Hospital de Santiago (1226), muy próximo al convento de San Francisco, adecuándose de esta manera al espacio residual disponible de la periferia urbana, pero estratégicamente situado en una encrucijada caminera, como ya hemos visto.

Si tenemos en cuenta que el ideal de pobreza se reflejó en un «monasterio pequeño y humilde, como entonces se usava», según cuenta el Padre Salazar, esta zona semidesértica, entre el campo y la ciudad permitía realizar la labor de los frailes en un mejor marco. Ahora bien, cabe la posibilidad de que en un primer momento los frailes se establecieran en un recinto provisional, incluso en algún edificio ya existente, como una pequeña ermita o similar, que en el caso de otras muchas ciudades, podía estar situada a cierta distancia del casco urbano. En una segunda fase, que para el caso de Talavera situaríamos en torno a la década de 12301240 , se busca un nuevo emplazamiento que suele ser a menudo en el inmediato espacio extramural ${ }^{64}$; en una zona de extramuros se ubica el convento talaverano como ya hemos visto.

Si bien esta evolución es susceptible de un análisis más detenido de las implicaciones socioespaciales de la fundación franciscana en Talavera, resaltamos el carácter marginal y periférico del emplazamiento primitivo, como una consecuencia de la presunta competencia que se establece con el clero local.

Otros indicadores para poder situar el origen de San Francisco el Viejo se relacionan con las disposiciones legislativas de la orden. Tras la muerte del santo, en 1226, la primera medida papal viene por la bula "Quo elongatis de 1230, promulgada por Gregorio IX en la que se coloca a los franciscanos en una perspectiva histórica que se alejará del ideal primitivo. Otra bula del mismo año, "Si Ordinis Fratum Minorum» concedía y animaba a los fieles para levantar conventos de la orden; llamada que sin duda debe relacionarse con las fundaciones de casas franciscanas por parte de familias nobles de las ciudades. Una medida que implicaba un acercamiento a la iglesia secular, fue la de 1237 mediante la bula "Quoniam abundavit», en la que el papa exhortaba a los obispos y prela-

64 MARTínez AguiRRE, Javier, «Espiritualidad franciscana y arquitectura gótica: del recelo a la revitalización" en VI Semana de Estudios Medievales (Nájera, 31 julio-4 agosto 1995). Logroño, 1996, págs. 119. En Italia se da este proceso de forma muy clara como ha estudiado M. D'ALATRI, en "Y piú antichi insediamenti dei mendicati nella provincia civile di campagna" en Mélanges de l'École Française de Rome. Moyen Âge. Temps Modernes, 89 (1977), págs. 575-576. 
dos que obtuvieran un consenso en los curas locales para la construcción de iglesias conventuales ${ }^{65}$.

Esta serie de disposiciones papales pueden orientarnos a la hora de marcar referencias cronológicas. Una vez más nos inclinamos por una fundación del monasterio en su primitiva ubicación, extramuros del Arrabal Viejo, en la década de 1230.

Veamos ahora otras referencias textuales acerca del conjunto monacal. En la documentación disponible acerca del Hospital de Santiago se recoge la ubicación de San Francisco como puntos de orientación de sus espacios ${ }^{66}$, o para delimitar tierras, propiedad de los mismos: "Otra haça de tierra que podrá haser otras tres fanegas, que está entre la casa del dicho Ospital e Sant Françisco", "Yten otra tierra çerca de Sant Françisco, que se dize de los Hornos» ${ }^{67}$. Esto viene a reforzar ese carácter marginal del lugar al que antes aludíamos, zonas de huertos y de labor, junto al caserío.

En las crónicas locales hallamos una repetida alusión al convento de San Francisco como situado al oeste de la villa en el lugar de la ermita de la Magdalena ${ }^{68}$. Algunos, además, como el padre Torrejón, recogen una tradición local acerca de la familia fundadora del convento claustral:

"La tradición que hay en esta villa es que lo fundaron unos cavalleros muy ricos y de gran nobleza que se llamavan los calderones, pero si fue uno o muchos los que hiçieron este monasterio no se sabe ni ay noticia como es cosa tan antigua.... ${ }^{69}$.

65 CuAdRAdo SÁNCHEZ, Marta, «Un nuevo marco socioespacial: Emplazamiento de los conventos mendicantes en el plano urbano» en VI Semana de Estudios Medievales (Nájera, 31 julio4 agosto 1995). Logroño, 1996, págs. 102-103.

66 Por ejemplo, en la visita del Hospital de 1494 (A.H.N. Órdenes Militares, Santiago, Mss. 1067-C) se sitúa el centro santiaguista señalando "qués çerca del monasterio de Sant Françisco, junto con'l arraual de la dicha villa de Talauera". Más adelante, describiendo otras dependençias dice "en el otro costado, hazia el monesterio de Sant Françisco, están çiertas sennales de edifiçios...". DEL CERRO dEL VALLE, op. cit.

67 Ibidem, pág. 93. Igualmente, en la visita de 1525: «Una tierra con dos olivas cabe San Françisco..."; "Yten que en un corral que la dicha yglesia tiene delante qu'está fecho plaça e ay mucha anchura, mandósele que al cabo d'él hazia San Françisco el Viejo, porque se pueden haçer dos casas...", pág. 154.

68 Así lo citan fray Andrés de TORREJón en su obra Libro de las Antigüedades de Talavera, Talavera, 1596. Biblioteca Nacional, Mss. sig. 1.498, cap. XIV. Cosme GómEZ TEJADA DE LOS REYES, Historia de Talavera, antigua Elbora de los Carpetanos, Talavera, 1651. B.N., Mss. sig. 8.396, cap. 14. Y Francisco de Sото, Historia de la antiquísima ciudad y colonia roma Elbora de la Carpetania, hoy Talavera de la Reyna, Talavera, 1722, fol. 111.

69 La antigüedad, fundación y nobleza de la noble villa de Talavera, escriviola el Padre Fray Andrés de Torrejón...reparábala el Padre fray Alonso de Ajofrín. Talavera, 1646, Mss. de la Real Academia de la Historia, fol. 233. 
Evidentemente, estas crónicas tienden a ensalzar aspectos de dudosa veracidad histórica por lo que hay que tomar sus noticias con muchas precauciones. La familia Ortiz Calderón a la que alude Torrejón, está documentada en Talavera en el siglo XIV, y relacionada con la fundación del monasterio de Santa Catalina de la Orden de San Jerónimo ${ }^{70}$; ante la falta de referencias documentales de esta familia, en la época del establecimiento franciscano en la villa, no puede asegurarse que fueran artífices de la fundación. Cabe la posibilidad de que un linaje similar hubiera promocionado su establecimiento en el siglo XIII, fenómeno lógico, por otra parte, teniendo en cuenta la aceptación que el discurso mendicante tiene entre las oligarquías y los sectores burgueses en las ciudades donde se asientan.

\subsection{El monasterio}

Prosigue Torrejón en la descripción del complejo conventual apuntando que «tenía yglesia y claustro y todas las demás ofiçinas neçesarias para el seruiçio del convento y fuera del claustro auía una huerta que permaneçe...el capítulo adonde se juntauan a tratar los negoçios de la orden y de la haçienda era una capilla del claustro con advocaçión de la bien auenturada Sancta Clara" ${ }^{71}$. En definitiva se componía de los típicos elementos de un recinto monacal: parte residencial, iglesia, claustro y huerta.

El único documento gráfico que nos ha quedado del convento es una imagen de la iglesia, convertida ya en la ermita de la Magdalena, que forma parte de una magnífica panorámica, realizada en acuarela por el holandés Anton Van den Wyngaerde ${ }^{72}$, y fechada en 1567. El aspecto que ofrece el edificio es el de un templo mudéjar con ábside semicircular,

70 Juan Ortiz Calderón, sobrino del fundador del monasterio, el cardenal toledano Pedro Tenorio, moría en 1397 y en su testamento disponía que parte de sus bienes fueran empleados en la fundación de un monasterio jerónimo cerca de Talavera. Acerca del origen de Santa Catalina de Talavera vid. Rafael SÁNCHEZ SESA, «Don Pedro Tenorio y la reforma de las órdenes monásticas en el último tercio del siglo xIV: La vinculación del prelado a la espiritualidad jerónima», En la España Medieval, 18 (1995), págs. 289-302. Y José Carlos VIZUETE MENDOZA, «La estructura de la propiedad agraria en Castilla-La Mancha en el siglo XV: Las órdenes monásticas" en Actas del 1º Congreso de Historia de Castilla-La Mancha. Toledo, 1988, tomo VI, págs. 27-46.

71 TORREJón y AJOFRín, op. cit., fol. 233 v. La capilla de Santa Clara es mencionada también en un documento de 1491 (Archivo de la Colegiata de Talavera, Caja 43, n 4): «estando dentro del monesterio de Sant Françisco extramuros desta dicha villa de Talauera et estando en la capilla de Santa Clara del dicho monesterio..."

72 Richard L. Kagan, Ciudades españolas del Siglo de Oro. Las vistas españolas de Anton Van den Wyngaerde. Madrid, 1986, págs. 347-348. 
dispuesto al este, y abovedado al interior ${ }^{73}$. Nave rectangular con techumbre a dos aguas y rematada con espadaña para campanario. En su estructura básica seguía algunas disposiciones conciliares dadas en materia de arquitectura conventual: "De ningún modo las iglesias deben ser abovedadas, excepto el presbiterio. Por otra parte, el campanario de la iglesia en ningún sitio se construirá a modo de torre» ${ }^{74}$. La cabecera de la iglesia, junto con la fachada occidental es la que adquiere mayor relevancia desde el punto de vista litúrgico y místico. Es el espacio atribuido a la consagración y donde se celebra el acto central de la liturgia; como aclara Marta Cuadrado, esto se traduce en unos diseños de la capilla mayor más vanguardistas que implican el abovedamiento de su interior, y la ubicación de vanos para la luz ${ }^{75}$.

En el caso que nos ocupa, el ábside con bóveda interna está constatado como ya hemos visto, y la presencia de vanos o ventanas se vislumbra en la ilustración de 1567. El esquema de ábside mudéjar seguido en la obra de San Francisco el Viejo, con una disposición de varios paños, probablemente siete a juzgar por la imagen, parece tener paralelos con el de Santiaguito u Hospital de Santiago. En éste se sigue un diseño de "ábside poligonal de siete lados, inscrito en una semicircunferencia, y un tramo recto de dos paños, sin resalte en planta entre ambos elementos. Se asienta sobre un basamento de mampostería con hiladas de ladrillo" ${ }^{76}$. Por los restos hoy día visibles se deduce que la parte de la capilla mayor y ábside debió de desaparecer en la demolición de principios del siglo XVIII.

Los edificios franciscanos respondían en su aspecto estético al fundamento doctrinal del fundador, la humildad como hermana de la pobreza. Ideal traducido a la arquitectura mendicante que le haría diferenciarse de los monasterios cistercienses ${ }^{77}$. Austeridad en el diseño procurando la

73 Según describe TeJADA DE los REYES, (op. cit.), el interior de la capilla mayor era "de bóveda bien labrada"s.

74 Estas se recogen en el Concilio de Narbona de 1260. Vid. M. BIHL; "Constitutiones generales edita in Capitulo generali celebrati Narbonae an. 1260, Assisi a. 1279 atque Parisii an. 1292» en Archivum Franciscanum Historicum, 34 (1941) págs. 37-94 y 284-319, y Joaquín YARZA, Fuentes y documentos para la historia del arte. Arte Medieval II. Románico y gótico. Barcelona, 1982, pág. 237.

75 Cuadrado Sánchez, Marta, Arquitectura de las órdenes mendicantes. Cuadernos de Arte Español. Madrid, Historia 16, 1993, pág. 10.

76 ABAD CASTRO, Ma C. Arquitectura mudéjar religiosa en el Arzobispado de Toledo. Toledo, 1991, tomo Il, págs. 219-223.

77 MARTínez DE AgUIRRE, J., «Espiritualidad franciscana y arquitectura gótica», op. cit., pág. 115. 
eliminación de ornamentos superfluos; edificiis temperatis et humilibus se apuntaba en el capítulo general franciscano de Asís en $1316^{78}$.

Por los restos hoy día visibles en superficie puede deducirse que los muros de esta iglesia estaban fabricados con aparejo toledano alternando el ladrillo y la mampostería, técnica muy común en nuestro ámbito geográfico. El uso de las verdugadas de ladrillo y los cajones de mampostería nos sitúan en el mudejarismo arquitectónico. Los muros perimetrales de la iglesia están orientados de $\mathrm{E}$ a W, siguiendo la regla común de este tipo de edificio.

El interior de la iglesia, una nave única, como solía ser las iglesias de los conventos franciscanos ${ }^{79}$, pero amplia, con algunos vanos, al menos en el muro sur. Unos pilares de ladrillos flanqueaban la capilla mayor según se describe en la carta de donación del edificio a la cofradía de la Magdalena en $1536^{80}$. En cuanto a las dimensiones del edificio su longitud era algo menor que la del Santiaguito, siendo ésta de unos $20 \mathrm{~m}$. con el ábside incluido.

La arquitectura franciscana medieval parece seguir una diversidad dentro de la unidad, en palabras de Marta Cuadrado; denota una adaptación a lo que veían en los lugares de asentamiento, en lo que se refiere a los condicionamientos físicos, tradiciones constructivas de la zona, etc. siempre y cuando estuviera todo en función de los objetivos principales: la liturgia y la predicación ${ }^{81}$. Si establecemos una hipótesis comparativa entre la iglesia franciscana y la del Hospital de Santiago ${ }^{82}$, muy próxima a aquella, podemos fijar unas conclusiones provisionales: al igual que la capilla hospitalaria, la de San Francisco era en realidad una iglesia conventual, por lo tanto no necesariamente de grandes proporciones. Además, teniendo en cuenta los aspectos estilísticos, la presencia primero del románico, de manera muy esporádica, y después el gótico, asociados a la impronta mudéjar en los edificios religiosos de la zona durante el siglo XIII, con representaciones tan elocuentes como el ábside del referido hospital o el de la iglesia de El

78 CuAdRAdo SÁNCHEZ, M. «Arquitectura franciscana franciscana en España (siglos XIUI y XIV)" en Archivo Iberoamericano, LI (1991), pág. 59

79 Cuadrado, Arquitectura de las órdenes..., op. cit., pág. 12.

80 Vid. documento 2 en el anexo.

81 Cuadrado Sánchez, op. cit., pág. 8. Idem, «Arquitectura franciscana...», op. cit.

82. Ma Concepción ABAD CASTRO, Arquitectura mudéjar religiosa en el Arzobispado de Toledo. Toledo, 1991, vol. I, pág. 153. Además sobre esta iglesia mudéjar puede verse el artículo de Michel TERRASSE, "Talavera Hispano-musulmane: Notes historico-archéologiques" en Mélanges de la Casa de Velázquez, vol., VI (1970), págs. 79-112. Y Conde de CeDILlo, Catálogo monumental de la provincia de Toledo. Toledo, 1959, pág. 327. 
Salvador de Talavera, hay paralelos evidentes que indican un uso común de soluciones arquitectónicas similares en esta centuria. Por lo tanto, la iglesia conventual de los mendicantes parece responder a los mismos modelos de templo de nave única, con ábside en la cabecera ${ }^{83}$.

Si establecemos este paralelo arquitectónico la cronología del edificio franciscano también se puede ir aclarando, así como la fecha de construcción del complejo conventual ${ }^{84}$.

No disponemos de muchas más noticias desde el punto de vista arquitectónico. Tan sólo cabe señalar que los indicios arqueológicos que se evidencian en la superficie del solar, en la actualidad sólo permiten vislumbrar la extensión del recinto pero no su distribución y funcionalidad ${ }^{85}$.

El devenir del antiguo convento franciscano a finales del siglo xv está unido al proceso de reforma de la orden y el traspaso de la comunidad al nuevo monasterio de San Francisco que funda el arzobispo de Granada fray Hernando de Talavera en 1494. Tras su abandono, el edificio, según cuenta Torrejón, fue derribado: «después que los padres claustrales la dexaron (no) han biuido en ella otros religiosos sino que se derribó la casa y quedó solamente la yglesia que es agora hermita de la magdalena» ${ }^{86}$. Sin embargo, durante algunos años quedó el monasterio e iglesia a expensas de las limosnas que recogía un beato, actitud que levantó los recelos de la comunidad franciscana observante ${ }^{87}$. La edificación que se mantuvo en pie con toda seguridad fue la iglesia, cuya capilla mayor estaba, al menos desde la segunda mitad del siglo xv, bajo el patronazgo de la familia Zúñiga.

83 Sobre el ábside mudéjar toledano vid. Ramón Montora INVARATO, «Sobre los ábsides mudéjares toledanos y sus sistema de trazado» en Al-Andalus, XXXVIII (1973), págs. 460-463.

84 Las similitudes estructurales y compositivas entre la iglesia de Santiago y la capilla de la Magdalena que puede verse en la panorámica de Wyngaerde de 1567 nos sugiere esta idea. De acuerdo con esas premisas y tomando como referencia cronológica la de la capilla de Santiago, década de 1220 , proponemos un margen entre 1220 y 1240 para la construcción del convento de San Francisco.

85 En 1994 el arqueólogo talaverano Alberto Moraleda y el autor de este artículo presentaron al Excmo. Ayuntamiento un pequeño informe advirtiendo la existencia de éstos restos, sitos en el Paseo Juan de Mariana, en el solar conocido popularmente como huerta de Benito, y solicitando que se efectúen los pertinentes trabajos arqueológicos en la superficie que ocupó el desaparecido convento de San Francisco el Viejo.

86 TORREJón y AJOFRín, op. cit., fol. 233.

87 Así se deduce del acuerdo que toma el regimiento en sesión de 28 de enero de 1502: « Este dicho día los dichos señores mandaron dar? su petiçión para el arçobispo nuestro Señor sobre que mande a los frayles de San Francisco el Nuevo que no ympidan que un buen onbre beato que tomó (...) e alumbra la casa de Sant Françisco el Viejo que pida e demande limosna para la lámpara para la dicha casa del monesterio de Sant Françisco el Viejo porque se lo proyben" (Archivo Municipal de Talavera, Libro de Acuerdos de 1502, fol. 54 v.) 
Por acuerdo firmado el 4 de agosto de $1536{ }^{88}$, don Pedro Zúñiga daba facultad «e donaçión a la dicha cofradía de la Madelena e a los cofadres...para que pasen a la dicha capilla de Señor San Françisco el viejo la aduocaçión de la dicha cofadría". Con esta ocupación la cofradía, que hasta entonces había estado en una ermita junto a la iglesia de San Ginés ${ }^{89}$ encontraba una nueva sede. En la escritura se recogen además algunas obligaciones que contraía la cofradía al disfrutar del uso de la capilla entre ellas "hazer...un altar e un retablo e una ventana en el cuerpo de la dicha capilla y dentro de quatro años cumplidos desde oy dicha dia han de hazer una casita para donde esté e rresida un santero o santera». Además don Pedro establecía su derecho y el de sus descendientes y hermanos para hacer enterramientos en la capilla «junto al altar donde los pilares de ladrillo adentro y allí no se pueda enterrar otra nynguna persona syn mi voluntad».

La cofradía de la Magdalena se mantuvo en esta capilla hasta 1703, fecha en la que se arruinó y paso su imagen y culto a la parroquia de San Clemente ${ }^{90}$. Parte de sus materiales fueron empleados, previa autorización del Consejo de Gobernación del Arzobispado de Toledo, en la construcción del convento de Padres Carmelitas junto a la iglesia de San Andrés ${ }^{91}$.

\subsection{Situación económica del convento}

Escasos son los datos que tenemos acerca de la hacienda de los frailes en Talavera. Su decidido carácter claustral convierte al monasterio de San Francisco en un centro mendicante expuesto a un cierto nivel de adquisiciones fruto de las beneficios espirituales que administraban a los fieles con recursos económicos. Amén de los bienes que el convento ob-

\footnotetext{
${ }^{88}$ Archivo de la Colegiata de Talavera, Caja $519, n^{\circ} 8$. Escritura del escribano público de Talavera, don alonso Rodrigues de Madrigal.

89 PACHECO, C., El Barrio de la Puerta de Cuartos..., op. cit., pág. 130. Este cambio de sede sin duda se debió a la fundación del nuevo convento de Santo Domingo, que la orden de predicadores realizó en 1520 sobre la antigua parroquia de San Ginés, obligando a la cofradía de la Magdalena a buscar un nuevo emplazamiento.

90 Según recoge Francisco de Soro en su crónica de Talavera de 1722, tras su ruina no quedó más rastro que una huerta y una alberca, junto a la que el siglo pasado fue instalada la popular Fuente de los Leones. En un plano de Talavera del Instituto Geográfico y Estadístico de 1884 tan sólo figura un estanque en el área en donde se había enclavado el monasterio de San Francisco.

91 Nicolau Castro, J., «Datos documentales sobre la Colegiata de Talavera de la Reina» en Anales Toledanos, vol XV (1982), pág. 25.
} 
tenía por aniversarios, memorias y demás recursos temporales que repercutían en la renta del mismo, hay que tener en cuenta las donaciones que algunas familias de la villa realizaron para engrosar las propiedades franciscanas.

La crónica de Torrejón habla de este tipo de atenciones con los frailes: "mandavan muchos en sus testamentos haçer alli benefiçios espirituales, como decir missas, treintanarios y aniversarios, dándoles rrenta y haçienda por los que dotavan para que fuesen perpetuos y les davan limosnas particulares de graçia por que rrogasen a Dios".

No obstante no disponemos de suficiente información como para establecer un cuadro de propiedades y bienes de San Francisco el Viejo. Según refleja Suárez Álvarez, dentro del panaroma de haciendas de instituciones de regulares talaveranos, el monasterio de Santa Catalina asumía, en el siglo $\mathrm{xV}$, el primer puesto en cuanto a volumen y número de propiedades rústicas y urbanas, seguido del Monasterio de San Clemente de Toledo, y el cisterciense de San Benito en Talavera ${ }^{92}$. Desgraciadamente no ofrece ningún dato acerca de San Francisco, lo que parece indicar una escasez de documentación que ha llegado hasta nosotros. También sugiere un volumen no excesivo de bienes raíces que son escasamente documentados.

De nuevo Torrejón informa de una carta de compra que hizo un custodio del monasterio fransciscano de una casa que después, a partir del siglo XVI, fue hospital de San Bartolomé ${ }^{93}$.

En realidad, el único instrumento localizado para poder aproximarnos al problema de la hacienda franciscana es un documento de los años 90 del siglo $\mathrm{XV}$, poco antes de su cierre definitivo por el proceso de reforma y traslado al nuevo convento ${ }^{94}$. En junio de 1491 se hizo escritura de codicilio de doña María de Prada, mujer del difunto Álvaro de Ávila; en la misma manda dar "al monesterio de esta dicha villa dosçientos e cinquenta maravedís» que la doña María tenía de censo sobre «una huerta que tiene Nicolás de la Peraleda» junto al cementerio judío de Talavera, en la parte norte de la villa. A cambio, el monasterio se obli-

92 Suárez Álvarez, M J., La Villa de Talavera y su Tierra en al Edad Media (1369-1504). Oviedo, 1982, págs. 260-261.

93 Hoy en la calle Ramón y Cajal de Talavera.

94 Archivo de la Colegiata de Talavera, "Traslados de las escripturas que subçedieron en la mesa capitular por vacaçión del monasterio de San Françisco el Viejo desta villa: Derecho y títulos de la mesa capitular de los çensos que dejaron los frailes de San Françisco. 1491-1495". Caja $43, n^{\circ} 4$. 
gaba "a deçir cada año tres fiestas... una misa y una vegilia cantadas", una el día de Santa María del mes marzo, en la iglesia de Santa María, capilla de Sant lldefonso; la otra por el día de San Sebastián y otra por Santa Ana, que debían celebrarse en el mismo monasterio de San Francisco.

Meses más tarde, en 1492, previa autorización que fray Sancho de Ontañón, ministro provincial de Castilla, dio al padre guardián y frailes del monasterio el 7 de noviembre de 1491 para «poder dar e troquar e cambiar las dichas heredades e posesiones e çensos e todas las otras cosas e bienes", fray Alfonso de Aguilar, guardián del monasterio, y el bachiller fray Diego Ros, fray Juan de Cantarranas, fray Alfonso de Solaya, fray Diego de Cota, fray Juan de Caloña, como representantes de la comunidad firmaban escritura de trueque y cambio con doña María Álvarez de Toledo, mujer del difunto regidor de Talavera, don Ruy García de la Rúa. En ésta, los frailes cambiaban el censo obtenido por el codicilio de doña María de Prada, de los doscientos cincuenta maravedís a cambio de otro censo entitéutico de igual cantidad y una gallina que María Álvarez de Toledo tenía sobre unas casas en los arrabales viejos. Operaciones con cierta especulación como ésta, sobre los bienes obtenidos, plantean interrogantes acerca del verdadero capital de que dispuso el monasterio.

Por último, otra escritura de cambio y trueque en los momentos de creación del nuevo convento observante de San Francisco, 16 de febrero de 1495 , se concierta entre fray Diego de Vitoria, vicario y lugarteniente del guardián del monasterio de San Francisco el Viejo, y con licencia de Sancho de Hontañón, y don Fernando de Ayala comendador, y Ruy García Suárez, vecino de Talavera, en nombre de fray Hernando de Talavera, arzobispo de Granada. En el acuerdo se cambian ochocientos maravedís de censos que tenían los franciscanos sobre dos casas que estaban en los límites del recinto del nuevo convento de San Francisco el Nuevo, por diferentes censos de doscientos cincuenta, doscientos y trescientos cincuenta maravedís, sobre otros censos respectivos que tenían los representantes del arzobispo. Esta debió de ser la última operación que llevaron a cabo los claustrales en su hacienda, pues poco después los derechos sobre estas escrituras pasan a la iglesia mayor el 6 de junio de 1495. Para entonces, el monasterio de San Francisco el Viejo debió de perder sus atribuciones legales para realizar cambios, y compra-ventas de propiedades. La reforma estaba en marcha, aunque el traspaso al nuevo convento observante no se realizaría hasta 1498. 


\section{PAPEL DEL CONVENTO DE SAN FRANCISCO EN EL PANORAMA RELIGIOSO LOCAL}

La condición de frailes claustrales que tenían los religiosos del monasterio talaverano les valió la adquisición de una determinada forma de proceder en el aspecto hacendístico. La cuestión originaria de la pobreza que San Francisco había defendido para sus hermanos de la orden quedó con el tiempo relegada a un segundo plano, al tiempo que los conventos y centros de frailes menores se iban convirtiendo en instituciones con un aceptable nivel de rentas y posesiones. Sin embargo, en todo este proceso hay que analizar el papel que juegan los frailes en aquellas comunidades urbanas en donde están encarnados y cual es su trascendencia a nivel doctrinal y religioso. En la medida en que los mendicantes van creando un círculo de simpatizantes y bienhechores de su causa, va aumentando el prestigio del convento.

Para el caso de Talavera, el establecimiento de la comunidad franciscana supone un cierto factor de garantía de la buena salud, a nivel religioso, que vive la villa en el siglo XIII. Sin duda, la principal dedicación que los frailes tenían era la del estudio y la predicación al vecindario talaverano, amen de otros asuntos temporales que iban ligados a la adquisición progresiva de esos recursos materiales y a su administración, hecho patente en la última fase del convento, antes de la reforma.

Según la crónica del jerónimo Torrejón se distinguieron por la preparación teológica que tenían los miembros de esta comunidad de San Francisco: "Auía en él (convento) muchos religiosos y personas graues graduadas en Theología a lo qual les era permitido según el modo de biuir que entonçes tenían, lo qual consta por las escripturas conventuales que haçian, adonde se nombran algunos con los grados que tenían... "95.

Esta formación se traducía en un cierto monopolio en el panorama catequizador en la villa, tanto en las capas sociales bajas como en los círculos privilegiados locales.

Las relaciones que los frailes talaveranos tuvieron con el poder civil resultan cuanto menos cordiales. Esta concordia con las autoridades del

95 TORREJón y AJOFRín, op. cit., fol. 233 v. Se deduce de esta refencia que existían una rica documentación procedente del convento de San Francisco que desgraciadamente no hemos localizado, si bien pensamos que pudo desaparecer en el proceso de exclaustración del otro convento franciscano, llamado San Francisco el Nuevo, en 1821. El padre Torrejón sin duda tuvo oportunidad de consultarla y contrastarla con la de su monasterio de Santa Catalina. 
concejo se vislumbra en el documento de 1296 ya aludido. La carta se valida con el sello "del convento de frailes menores", junto con el de otras instituciones de la villa como el propio concejo, y el de los comendadores de diferentes órdenes militares (Santiago y Calatrava), así como el cabildo de canónigos y clérigos. Por tanto, es indicativo que si los mendicantes firman un documento en donde están representados todos los poderes civiles y religiosos locales, es porque en esa época ya se han ganado la confianza de las autoridades, y han alcanzado un nivel de relación y aceptación de la comunidad talaverana que les permite estar presentes en asuntos de relevancia política.

Ahora bien, a lo largo de la etapa claustral de los franciscanos en Talavera la situación va generando una serie de tensiones que no siempre quedan patentes en la documentación. Sin embargo disponemos tan sólo de una referencia a un pleito que los religiosos «de San Francisco de Santa Clara de Talavera" mantuvieron con la Colegiata, máximo exponente del poder eclesial en la villa. Por la mención que hemos localizado se especifica que se llegó a un proceso de excomunión en el año $1485^{96}$ que tuvo que sentar una base, sin duda intencionada, para la posterior causa de reforma de los claustrales e imposición de la Observancia. Otro pleito en el que intervino uno de los frailes profesos de San Francisco se dio en 1493 , en plena etapa de transición a la Observancia ${ }^{97}$.

\subsection{El monasterio como espacio funerario}

Los aspectos relacionados con la muerte en la Baja Edad Media nos sitúan ante una perspectiva de la mentalidad social imperante en la época con respecto al óbito y todo lo que éste conllevaba.

Como han demostrado algunos autores como Fernando Martínez Gil ${ }^{98}$, entre la población acomadada se da un interés por los enterramientos en sagrado, pero en las propias iglesias. Si bien en un primer momento se opta por el exterior de las iglesias parroquiales, poco a poco, la confianza que van generando las comunidades de mendicantes en la población objeto de sus predicaciones, se inclinan por la sepultura en los interiores de

\footnotetext{
96 Archivo de la Catedral de Toledo, Repertorio Universal del Archivo. 1727, fol. 563. sig. $V .12^{\mathrm{a}} 1^{\circ}, 1^{\circ}$. Consultando con el archivero para intentar localizar el documento se nos dijo que no existía en la actualidad.

97 Archivo General de Simancas. Registro General del Sello, 1495, octubre, 1- fol. 268.

98 Martínez GiL, Fernando, La muerte vivida: Muerte y sociedad en Castilla durante la Baja Edad Media. Toledo, 1996.
} 
las iglesias conventuales. $Y$ entre éstas los conventos franciscanos se llevan la palma ${ }^{99}$.

La prohibición de realizar enterramientos en el interior de las iglesias parroquiales se tradujo en un deseo de los feligreses, casi siempre acaudalados, de buscar su sepultura en los recintos conventuales de mendicantes, más transigentes en este asunto, amen de suponer una fuente de ingresos bastante significativa para la orden ${ }^{100}$. Con anterioridad, el papa Bonifacio Vill autorizó a franciscanos y dominicos la posibilidad de ofrecer sepultura en sus templos a quienes lo hubieren solicitado en vida.

En el plano arquitectónico estas necesidades de espacios funerarios se articulan mediante la proliferación, dentro del área sagrada, de pequeñas capillas o multitud de sarcófagos ${ }^{101}$ que vienen a definir una instrumentalización del espacio de la iglesia o el convento.

En ese fenómeno, cada vez más frecuente, de los enterramientos en el interior de iglesias o cementerios de religiosos, durante los siglos XIV y XV, los franciscanos suelen ser los más favorecidos. Sus conventos se benefician de los testamentos de personas principales de las ciudades y villas que mandan ser sepultados en estos recintos ${ }^{102}$.

Pero llegado el momento, la competencia que se establece con el clero regular y las iglesias parroquiales se hace evidente. En Talavera parece que la práctica de los enterramientos en monasterios llega a ser una costumbre habitual que iba en detrimento de los beneficios de las parroquias. La norma era « recibir sepultura en la parroquia correspondiente a la que se entregaba cierta cantidad por los derechos de sepultura; sin embargo, habia libertad para elegir un templo distinto si bien se establecía la obligación de entregar a su iglesia parroquial alguna pequeña donación como compensación por bienes de se le privaba en beneficio de otra" ${ }^{103}$.

Esta normativa se vio quebrantada en la villa a juzgar por la sentencia que dio el arzobispo de Toledo, don Juan Martínez de Contreras ${ }^{104}$ en

99 Jacques LE Goff, en su obra El nacimiento del Purgatorio (Madrid, 1981, pág. 317) constata igualmente el hecho de dominicos y franciscanos acogieron y fomentaron la sepultura de los laicos, sobre todo ricos y poderosos en sus iglesias y cementerios.

100 Martínez Gll, op. cit., pág. 93.

101 Cuadrado, Marta, Arquitectura de las órdenes mendicantes, op. cit., pág. 14.

102 Cantera Montenegro, Margarita, "El testamento bajomedieval» en Historia 16, n 161 (†989), págs. 32-38.

103 Cantera montenegro, op. cit., pág. 35.

104 Este prelado cuidó mucho de favorecer a su villa de Talavera, realizando incluso la mojonera del término antes de conseguir el cargo de la mitra toledana, así como un atención especial a la Colegiata de Santa María, que lleva su escudo en una de sus puertas. AA.VV. Los primados de Toledo. Toledo, 1993, pág. 89. 
1432. A petición del cabildo de la Colegiata y del vicario de Talavera y su arcedianadgo se ordena a los fieles de la villa que en caso de enterramiento en un monasterio, deben reservar la cuarta parte de los derechos que pagaren para la parroquia correspondiente ${ }^{105}$. Con ello el prelado toledano pretendía corregir una alteración del orden económico que suponía el «negocio» de la muerte, en el que paulatinamente parece que las órdenes regulares, y en especial, los franciscanos parecían ganar puntos de forma decisiva.

En nuestro caso, disponemos de alguna referencia que nos informa de la costumbre, que debió de ser común entre ciertos sectores de la nobleza local, de disponer en los testamentos el enterramiento en el recinto franciscano. Fray Andrés de Torrejón indica en su crónica de 1596 al respecto de esto que uenterravanse en la capilla deste monasterio los del linage que la fundaron, aunque Juan Ortiz Calderón y su primera mujer Ysabel Rodríguez tomaron capilla en la yglesia mayor adonde se enterró esta... y la segunda mujer de Juan Ortiz que se llamava Teresa Gonçález...También se enterravan en Sant Françisco otros cavalleros y señoras y particularmente ay memoria de Martín de Vargas ${ }^{106}$, que fue de un linage principalísimo en esta villa y por esta ocasión mandavan muchos en sus testamentos haçer allí benefiçios espirituales, como decir missas, treintanarios y aniversarios, dándoles rrenta y haçienda por los que dotavan para que fuesen perpetuos y les davan limosnas particulares de graçia por que rrogasen a Dios, por quien se les dava, y les pedían que fuesen (a los frailes) a sus enterramientos honrrándose de que se hallasen presentes a sus sepulturas» 107.

Esta campaña de reconocimiento de los frailes menores alcanza a diversos sectores de las oligarquías locales, que, a cambio de servicios espirituales ofrecen bienes y rentas al monasterio. En el testamento de doña Elvira de Ayala, esposa de don Fernán Álvarez de Toledo, señores de Oropesa, fechado el 17 de noviembre de 1411 se apunta la donación de

105 Sentencia fírmada en Ageda el 30 de agosto de 1432. Archivo de la Colegiata de Talavera, Caja 255, № 31 .

106 En otra parte de la obra de TORREJón se señala que «Martín de Vargas está enterrado en San Francisco el Viejo" En el siglo xv se registran algunos descendientes del linaje de los Vargas en Talavera, entre los que destacan Alonso de Vargas, regidor, y Diego de Vargas, alguacil mayor de la villa. Vid. SuÁrez Álvarez, Ma Jesús, La Villa de Talavera y su Tierra en la Edad Media (1369-1504). Oviedo, 1982. PACHECO JIMÉNEZ, César, «El regimiento en Talavera de la Reina en el siglo XV" en Cuaderna: Revista de estudios humanísticos de Talavera y su antigua tierra, no 6 , en prensa.

107 TORREJón, Fray Andrés, op. cit, cap. 10. 
1.000 maravedís a los monasterios de Santa Catalina (de la orden de San Jerónimo), al de San Benito y San Francisco de Talavera ${ }^{108}$.

Al menos en las últimas décadas del siglo $\mathrm{xV}$, el patrono de la capilla mayor de la iglesia conventual, lugar de enterramiento para los de su linaje, fue la familia de los Zúñiga, uno de cuyos representantes, Alonso de Zúníga alcanza el cargo de regidor del ayuntamiento talaverano ${ }^{109}$.

La inexistencia de fondos del archivo procedente de este monasterio nos ha privado de un conocimiento más exhaustivo de la casuística testamentaria del mismo.

\section{LA REFORMA DE LA ORDEN FRANCISCANA LLEGA A TALAVERA: SAN FRANCISCO DE LA OBSERVANCIA}

La reforma del clero regular toma especial impulso bajo el reinado de los Reyes Católicos ${ }^{110}$; el especial acento que ponen los monarcas en acelerar el proceso tiene su respaldo con la facultad que obtienen del papa Alejandro VI, en marzo de 1493, por la que autoriza que nombren personas para visitar y reformar conventos de monjas de cualquier orden religiosa. La reforma se extendió por todas las órdenes, de tal manera que los reyes encomendaron al cardenal fray Francisco Jiménez de Cisneros, la labor de la reforma monástica en todo el reino.

Cisneros, que había sido elegido Superior Provincial de los franciscanos en mayo de $1494{ }^{111}$ tenía una clara vinculación a la Regular Observancia, pero su estrategia para intentar la reforma de los claustrales iba progresivamente hacia la negociación con aquellas comunidades que todavía estaban enclavadas en el conventualismo. Sin embargo, en la última década del siglo $\mathrm{xV}$ algunos ministros provinciales conventuales, entre ellos el de Castilla, fray Sancho de Hontañón, empiezan a reformar sus propios conventos y a obligar su paso a la Observancia. Hemos visto, no

108 Archivo de los Duques de Frías, Sección de Oropesa, leg. 508, $\mathrm{n}^{\circ} 10$ y 15 . Referido en Alfonso Franco SILVA, «El proceso de señorialización de las tierras de Talavera de la Reina en el siglo xv: El caso de Cebolla y los Ayala» en Anuario de Estudios Medievales, 20 (1990), pág. 225.

${ }^{109}$ La vinculación de la capilla a esta familia se deduce del documeto de 1536 por el que hace donación de la misma a la cofradía de la Magdalena de Talavera. Vid. nota 88.

110 García ORo, J., La reforma de los religiosos españoles en tiempo de los Reyes Católicos. Valladolid, 1969.

11 Garcia Oro, J. El Cardenal Cisneros. Madrid, Biblioteca de Autores Cristianos, 1992, pág. 48. 
obstante, como el propio Hontañón concedía, todavía en 1491, facultad a los frailes del monasterio de Talavera para realizar operaciones de trueque de bienes para el convento, operación indicativa de la esencia conventual. Por lo tanto, su política reformadora debió de iniciarse poco después.

La insistencia de los monarcas, así como el empeño programático de Cisneros para su propia orden, incidieron en el paso progresivo de los claustrales talaveranos a la Observancia. La reforma cisneriana se inicia, según García Oro, en la primavera de 1493 cuando en la asamblea de superiores de la orden se esbozan posibles acuerdos secretos con los superiores conventuales ${ }^{112}$. Las relaciones de los conventuales con los Observantes va en detrimento a partir de entonces; medidas como la del breve Dudum certis iudicibus, del 18 de junio de 1494, concediendo a los observantes franciscanos las casas de los conventuales que voluntariamente quisiesen pasar a la Observancia. El proceso de reforma es inexorable y en los últimos años del siglo y principios del xvi se llega a consumar de tal manera que ya en 1517 se decreta la primacía de la rama observante como legítima representante de la orden, frente a los conventuales.

En el caso de la comunidad talaverana jugó un especial papel la figura del religioso jerónimo, confesor de la reina y arzobispo de Granada, fray Hernando de Talavera. Considerado como el gran inspirador de la reforma en lá etapa de los Reyes Católicos, a partir de $1485^{113}$, sus lazos con la villa natal produjeron una iniciativa fundacional. Dentro del ambiente de reforma generalizada de la orden que se vivía en 1494, en el que ya se había llegado al acuerdo con el ministro provincial de Castilla para abrazar la Observancia, y teniendo en cuenta las pocas posibilidades que les quedaban a los claustrales talaveranos, fray Hernando pide licencia al cardenal toledano Pedro González de Mendoza para instalar junto a la parroquia de Santa Leocadia un nuevo monasterio de observantes (vid. documento 1). La autorización de Mendoza, en octubre de 1494, da pie a Talavera para iniciar las obras del convento que estará listo en $1498{ }^{114}$, año en el

112 Idem, “La reforma de las órdenes religiosas en los siglos xv y xvl» en Historia de lglesia en España dirigida por R. García-Villoslada. Vol. Ill-1․ Madrid, 1980, pág. 287.

${ }_{113}$ AzconA, Tarsicio de, Isabel la Católica. Madrid, 1986, tomo II, pág. 190. El autor habla incluso de una reforma talaverana por el peso que tuvo fray Hernando en la empresa.

114 Para la ejecución de las obras tuvieron que comprarse varias casas en el entorno de Santa Leocadia y Puerta de Toledo, para ampliar las dependencias,y hacer una huerta. No obstante, algunos de estos inmuebles no fueron después integrados en el circuito del monasterio, por lo que se ordena a los alcaldes de Talavera que conforme a la tasación de los alarifes se page al vecino Per Álvarez Saçón el importe de dichas casas. (Archivo General de Simancas, Registro General del Sello, 1495, mayo, 18, fol. 154.) 
se produce el traslado de los algunos frailes claustrales junto con otros observantes venidos de fuera. Aquellos que no aceptaron la Observancia se marcharon a otros centros donde regía el conventualismo, según aclara el cronista Salazar.

Las propiedades y rentas del monasterio de San Francisco el Viejo fueron repartidas entre algunas instituciones religiosas talaveranas, pues la nueva regla observante impedía que los frailes tuvieran "haçienda ni rrenta». Según cuenta el Padre Salazar en su crónica de la orden: "El Reformador general adjudicó las rentas del monasterio al cabildo de los curas y beneficiados de la villa de Talauera. $Y$ en el sitio del sobredicho monasterio, después de muy arruinado, se fundó la hermita que llaman de la Madalena" 115. La escasa documentación localizada no representa mas que una pequeña parte. La iglesia mayor de Santa María o Colegial conservó algunas escrituras de censos y aniversarios que databan de 1491, y que fueron legalmente recibidas por el vicario general de Talavera y canónigo de la Colegial, don Sancho de Salzedo, el 6 de junio de $1495^{116}$. Por el relato de Torrejón sabemos que el monasterio de la Santísima Trinidad, también recibió derechos sobre algunas rentas; por su parte el nuevo convento de observantes conservó la mayor parte de las escrituras originales de las antiguas propiedades de San Francisco el Viejo.

El cambio de los restos de los frailes enterrados en el antiguo monasterio claustral se llevó a cabo treinta años después, cuando «el guardián alcanzó Breue indulto del señor Papa León X, para hazer translación de todos los huessos de los religiosos que auian muerto. Io quales todos con gran autoridad y acompañamiento de toda la villa fueron traydos y trasladados al Covento de San Francisco que aora es" 117 .

Con este traslado, comenzaba una nueva andadura la orden fransciscana en la villa de Talavera que se mantendrá hasta los procesos de exclaustración y desamortización en $1821^{118}$.

115 SALAZAR, op. cit., Libro III, pág. 256.

116 Archivo de la Colegiata de Talavera, Caja 43, expediente no 4. Vid. nota 94.

117 SalazAR, op. cit., pág. 257.

118 Desde entonces la iglesia del convento se convirtió en parroquia, asumiendo la jurisdicción de Santa Leocadia en las décadas centrales del siglo pasado; después como parroquia de San Francisco, hoy filial de Santa María. El edificio conventual se mantuvo hasta 1988, cuando una desafortunada política de destrucción del patrimonio histórico talaverano, acabó con todo el complejo monástico. 


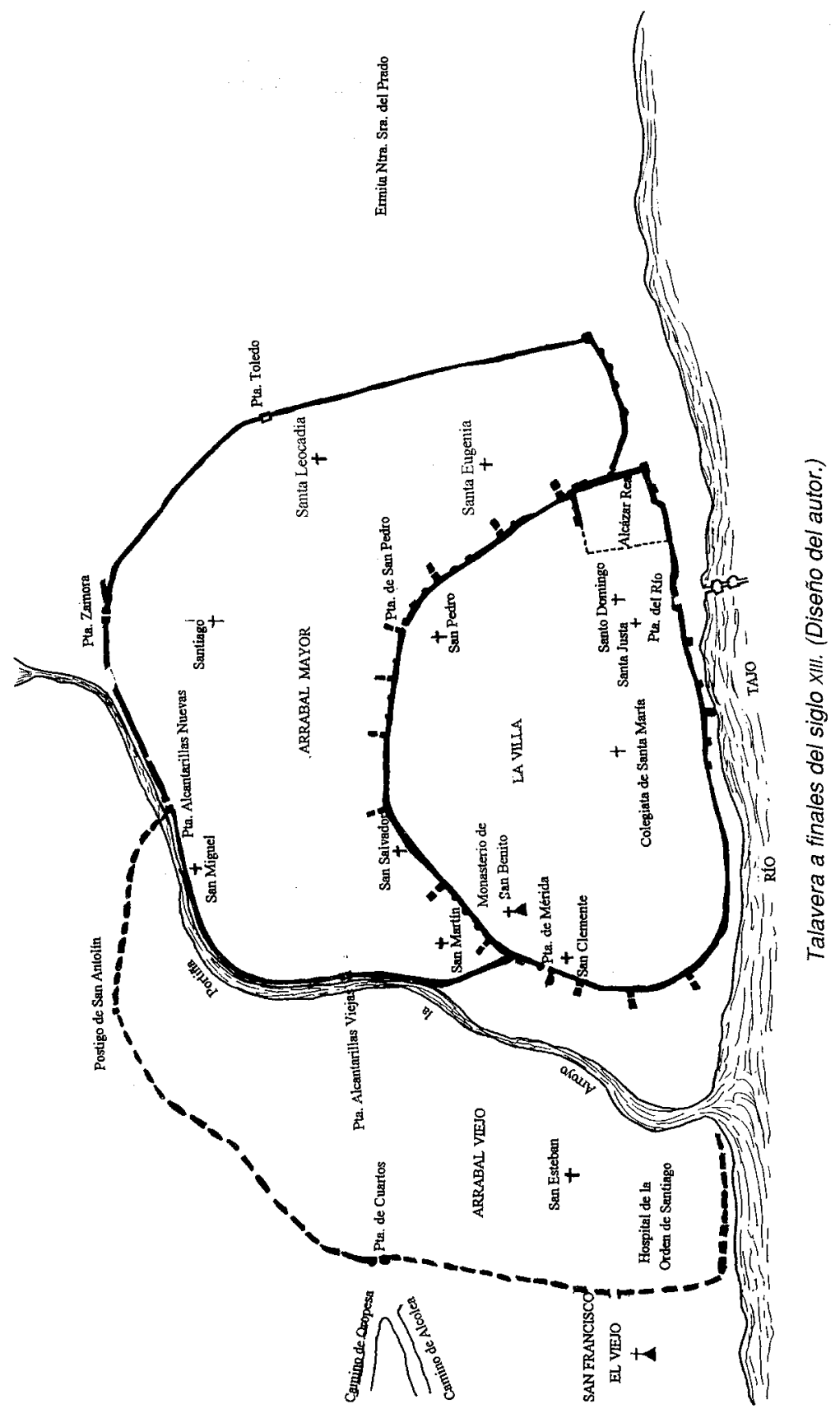


Franciscanos en la Castilla Bajomedieval: El monasterio de San Francisco...

\section{ANEXO DOCUMENTAL}

1494, octubre, 2. Guadalajara

Licencia que el cardenal don Pedro González de Mendoza dio a fray Hernando de Talavera para la fundación de un nuevo monasterio de la orden de San Francisco de la Observancia, junto a la iglesia de Santa Leocadia.

(Fuente: Transcripción inserta en la obra de Fray Andrés de Torrejón, ampliada por fray Alonso de Ajofrín: La antigüedad, fundación y nobleza de la noble villa de Talavera. 1646. Mss. Real Academia de la Historia, fols. 196 y 234-236).

«Don Pero Gonçalez de Mendoça por la diuina miseraçión, cardenal de España, Patriarcha de Alexandría, Arçobispo de la sancta yglesia de Toledo, primado de las Españas, Chaçiller Mayor de Castilla e Obispo de Siguença, a todas e qualesquier personas de qualquier estado, condiçión, preeminençia e dignidad que sean salud y bendiçión. Sepades que el mui reuerendo en Christo padre don frai Fernando de Talauera, por la graçia de Dios e de la sancta yglesia de Roma, Arçobispo de Granada, confesor y del Consejo del Rey de la Reyna, mis señores nos, enbió a façer relaçión que él, mouido por seruiçio de Nuestro Señor e por la mucha deuoçión que tiene a la orden e religión de Sant Françisco de Observançia, e ansi mesmo deseando proveer la mucha falta que en la nuestra villa de Talauera, donde él es natural, tiene de personas religiosas $y$ de doctrina y buen exemplo, querría y desea edificar en ? desta nuestra villa un monesterio de la dicha orden de Sant Françisco de Observançia, en algún sitio de la dicha villa que fuese conueniente e prouechoso, e sin perjuiçio de los clérigos de la dicha nuestra villa e veçinos della; y que entre otros sitios le pareçió que sería mejor el dicho monesterio y que sería más util y prouechoso para el pueblo (borrón) perjuiçio de los clérigos e benefiçiados de la dicha nuestra villa e veçinos della, junto a la yglesia perrochial de Sancta Leocadia de la dicha villa, incorporando la yglesia de la dicha perrochia en el dicho monesterio e façiendo la yglesia dél. Por ende que nos pedía e suplicaua le mandasemos dar e diesemos para ello nuestra liçençia e autoridad, mandando pasar e pasando la dicha yglesia de Sancta Leocadia con los anexos parrochianos e rrentas emolumentos della a una yglesia parrochial de la dicha nuestra villa que más cómoda e conuenible fuese, lo qual diçe se puede façer sin perjuiçio de los parrochianos de la dicha parrochia e de la mayor parte dellos porque, de setenta o ochenta parrochianos que diz que tiene, solo diez o doçe moran çerca y los otros asaz lexos de la dicha parrochia e mas çercanos a otras 
yglesias parrochiales. E nos, visto el buen zelo del dicho Arçobispo e considerando quanto en ello Nuestro Señor sea seruido, e queriendo condeçender a su petiçión e suplicaçión en nos es ayudar a su pío e sancto propósito, mandamos auer informaçión de todo lo susodicho e de la utilidad o perjuiçio que podría venir a la dicha nuestra villa e clérigos della de la fundaçión del dicho monesterio junto con la dicha yglesia parrochial de Sancta Leocadia, e donde e a que yglesia se podía pasar la dicha yglesia parrochial de Santa Leocadia que mas conueniente fuese a los parrochianos e clérigos; e mandamos cometer la dicha informaçión al bachiller Juan de Çentenera, nuestro uisitador en el dicho nuestro Arçobispado, el qual, por uirtud de la dicha nuestra comisión guardando el tenor e forma della uuo la dicha informaçión, e çerrada e sellada la enbió a nos; e uista el nuestro, pareçe por ella que el pueblo e veçinos de la dicha nuestra villa reçebía mucho prouecho e utilidad con las cosas espirituales en la ereçión e fundaçión del dicho monesterio en el dicho sitio e el culto diuino será augmentado e que los clérigos e benefiçiados de la dicha nuestra dicha villa, de justiçia ni de conciençia, no pueden impedir la dicha fundaçión e ereçión del dicho monesterio; e que deuíamos dar e conçeder la dicha yglesia de Santa Leocadia para la yglesia del dicho monesterio, e dar la dicha liçençia para edificar el dicho monesterio, mandar pasar la dicha parrochia de Sancta Leocadia, benfiçiados e parrochianos e rrentas della, con las campanas, ornamentos e libros e otras qualesquier cosas, a ella anexas, e perteneçientes, a la yglesia de Sancta Eugenia, la qual diz que es asaz grande e amplia e que non tiene en la dicha villa más de çinco o seis parrochianos, e que es las más çercana e comoda yglesia a los dichos parrochianos de Sancta Leocadia, e que allí la deuiamos mandar pasar e transferir. Para lo qual ansi façer, los dichos curas de Sancta Leocadia e Sancta Eugenia pasaron su expreso consentimiento ante notario público, e les plugo e plaçe de su propia o libre voluntad que se faga la dicha traspasaçión en la forma susodicha, con tanto que la dicha parrochia se aya de llamar de aquí adelante de Sancta Leocadia e Sancta Eugenia. Lo qual todo el conçejo, justiçia e regimiento e caualleros o escuderos, ofiçiales e omes buenos de la dicha nuestra villa nos enbiaron a suplicar, por una su petiçión, lo mandasemos así façer por seruiçio de Dios Nuestro Señor, que él será dello mucho seruido e el culto diuino augmentado, e el pueblo de la dicha nuestra dicha villa e veçinos della en las cosas espirituales mucho aprouechado. $Y$ considerando todo lo susodicho ser así e quanto Nuestro Señor será seruido de la fundaçión del dicho monesterio e el culto diuino augmentado, e los veçinos de la dicha nuestra villa e clérigos della aprovechados en las cosas espirituales, touímoslo por bien y, por el tenor de la presente, por nuestra autoridad ordinaria e como mejor podemos, e de derecho devemos, damos liçençia e facultad al dicho 
mui reuerendo en Christo Padre don fray Fernando de Talauera, Arçobispo de Granada que pueda, junto con la dicha yglesia de Sancta Leocadia, edificar, construir un monesterio y casa de la dicha orden a inuocaçión de Sant Françisco de Observançia, con sus claustros, dormitorios, campaniles, ofiçinas, e huertas e otras habitaçiones e moradas neçesarias para los frayles e personas que estouieren e moraren en la dicha casa e monesterio. E que pueda incorporar en el dicho monesterio e casa que fiçiere e fabricase, la dicha yglesia de Sancta Leocadia, la qual nos, desde agora para entonçes e desde entonçes para agora, en la mejor forma que podemos e deuemos, damos, conçedemos para el dicho monesterio con las condiçiones contenidas en el consentimiento de los dichos curas e parrochianos que para el lo dieren.E transferimos e pasamos la dicha perrochia de Sancta Leocadia a la dicha yglesia perrochial de Sancta Eugenia de la dicha villa de Talauera (...). En testimonio de lo qual mandamos dar e dimos la presente, firmada de nuestro nombre e sellada con nuestro sello, que fue fecha en la cibdad de Guadalajara a dos días del mes de octubre, año del naçimiento de Nuestro Señor Jessuchristo de mill y quatroçientos e noventa e quatro años».

\section{BIBLIOGRAFÍA}

ABAD CASTRO, Ma Concepción, Arquitectura mudéjar religiosa en el Arzobispado de Toledo. Toledo, 1991,

Abad Pérez, Antolín, O.F.M., «La biblioteca franciscana de Toledo (1284-1808)» en Anales Toledanos, vol. XX (Toledo, 1984), págs. 11-36.

Carrasco Lazareno, M. Teresa, "Los conventos de San Francisco y de Santo Domingo de la villa de Madrid (siglos XIII-XV). Breves consideraciones históricas, jurídicas y diplomáticas» en VI Semana de Estudios Medievales (Nájera, 31 julio-4 agosto 1995). Logroño, 1996, págs. 239-254.

Cendllo, Conde de, Catálogo monumental de la provincia de Toledo. Toledo, 1959, pág. 327. Crónicas Franciscanas de España. Volumen sexto: Crónica de la Provincia de Castilla por el Padre Salazar O.F.M., prólogo del Padre Antolín Abad Pérez, O.F.M. Edición facsímil de la de 1612. Madrid, Editorial Cisneros, 1977.

CuAdRADO SÁNGHEZ, Marta, "Un nuevo marco socioespacial: Emplazamiento de los conventos mendicantes en el plano urbano" en VI Semana de Estudios Medievales (Nájera, 31 julio-4 agosto 1995). Logroño, 1996, págs. 101-110.

Idem, Arquitectura de las órdenes mendicantes. Madrid, 1993.

De Azcona, Tarsicio, Isabel la Católica. vol. Il. Madrid, 1986.

Del Cerro del Valle, Ángel, La Encomienda Santiaguista del hospital de Talavera (14941537). Toledo, 1984

FERNÁNDEZ y SÁNCHEZ, Ildefonso, Historia de la Muy Noble y Muy Leal Ciudad de Talavera de la Reina. Talavera, 1896

Fernández, García, Historia de la Villa de Talavera. Talavera, 1560. Mss. de la B.N. sig. 1.722.

García de CoRTÁzAR, J. Ángel, La sociedad rural en la España Medieval. Madrid, 1988

García Oro, José, Francisco de Asís en la España Medieval. Santiago de Compostela, 1988. Idem, La reforma de los religiosos españoles en tiempo de los Reyes Católicos. Valladolid, 1969.

Idem, La lglesia de Toledo en tiempo del Cardenal Cisneros (1495-1517). Toledo, 1992. Idem, «El franciscanismo hispano de la Edad Media» en Verdad y Vida, XLV (1987). 
GómEZ MENOR, José, La antigua Tierra de Talavera: Bosquejo histórico y aportación documental. Toledo, 1965

Gómez TEJADA de los Reyes, Cosme, Historia de Talavera, antigua Elbora de los Carpetanos, Talavera, 1651. B.N., Mss. sig. 8.396.

GonzÁlez PALEnCIA, Ángel, Los mozárabes de Toledo en los siglos xII y XIII, 4 vols. Madrid, 1926-1930.

GRAÑA C $10, M^{a}$ del Mar, «Frailes, predicación y caminos en Madrid. Un modelo para estudiar la itinerancia mendicante en la Edad Media” en Caminos y caminantes por las tierras del Madrid medieval. Madrid, 1993

Idem, "Religiosos in via. Franciscanos y caminos en Castilla la Nueva (1215-1550)" en Actas del I Congreso de Caminería Hispánica. Guadalajara, 1993.

Guerra, José Antonio, San Francisco de Asís. Escritos. Biografía. Documentos de la época. Madrid, 1978.

Historia de Iglesia en España dirigida por R. García-Villoslada. Vol. IIl-1 «La Iglesia en la España de los siglos XV y XVI's. Madrid, 1980.

JimÉnez de Gregorio, Fernando, Los pueblos de la provincia de Toledo hasta finalizar el siglo XVIII. Talavera de la Reina. Toledo, 1983

López, Atanasio, O.F.M., La Provincia de España de los Frailes Menores, Santiago de Compostela, 1915, págs. 171-172.

MARTINEZ DE AGUIRRE, Javier, «Espiritualidad franciscana y arquitectura gótica: del recelo a la revitalización» en VI Semana de Estudios Medievales (Nájera, 31 julio-4 agosto 1995). Logroño, 1996, págs. 111-132.

Martínez Gil, Fernando, La muerte vivida: Muerte y sociedad en Castilla durante la Baja Edad Media. Toledo, 1996.

MERLO, Grado G., «Eremitismo nel francescanesimo medievale» en Eremitismo nel francescanesimo medievale. Atti del XVII Convegno Internazionale. Assisi, 1991.

PACHECo, César, El barrio de la Puerta de Cuartos: Historia social y cultural. Talavera, 1993. Idem, "Sínodo de Talavera: 24 de octubre de 1498» en La Voz de la Comarca de Talavera, $\mathrm{n}^{\mathrm{o}} 1$ (1992).

Peña Pérez, F. Javier, «Expansión de las órdenes conventuales en León y Castilla: franciscanos y dominicos en el siglo XIIl' en III Semana de Estudios Medievales (Nájera, 2-7 agosto de 1992). Logroño, 1993, págs. 179-198.

Porres Martín-Cleto, Julio, "Los franciscanos en Toledo" en Anales Toledanos, vol. XVII (Toledo, 1983), págs. 17-28.

Ríos Rodríguez, M" Luz, "Conventualismo y manifestaciones heréticas en la Baja Edad Media» en III Semana de Estudios Medievales (Nájera, 2-7 agosto de 1992). Logroño, 1993, págs. 129-160.

Rodríguez-Picavea Matilla, Enrique, La Villa y la Tierra de Talavera en la Plena Edad Media: Orígenes, consolidación y crecimiento de un concejo de realengo (siglos XIII-XV). Talavera de la Reina, Excmo. Ayuntamiento, 1996.

Rucquol, Adeline, "Los franciscanos en el Reino de Castilla» en VI Semana de Estudios Medievales (Nájera, 31 julio-4 agosto 1995). Logroño, 1996, págs. 65-86.

Soтo, Francisco de, Historia de la antiquisima ciudad y colonia roma Elbora de la Carpetania, hoy Talavera de la Reyna, Talavera, 1722.

SuÁrez Álvarez, Ma Jesús, La Villa de Talavera y su Tierra en al Edad Media (1369-1504). Oviedo, 1982.

Idem., «Las vías de comunicación en la zona de Talavera en el período bajomedieval» en Actas de las primeras jornadas de Arqueologia de Talavera de la Reina y sus Tierras. Toledo, 1992, págs. 201-214

TerRasse, Michel, "Talavera Hispano-musulmane: Notes historico-archéologiques", en Mélanges de la Casa de Velázquez, vol., VI (1970), págs. 79-112.

TORREJón, Fray Andrés de, La antigüedad, fundación y nobleza de la noble villa de Talavera, escriviola el Padre Fray Andrés de Torrejón...reparábala el Padre fray Alonso de Ajofrín. Talavera, 1646, Mss. de la Real Academia de la Historia.

ToRREJón, Fray Andrés de, Libro de las Antigüedades de Talavera, Talavera, 1596. Biblioteca Nacional, Mss. sig. 1.498.

VÁZQUEZ JANEIRO, Isaac, "Los estudios franciscanos medievales en España" en VI Semana de Estudios Medievales (Nájera, 31 julio-4 agosto 1995). Logroño, 1996, págs, 43-64. 